\title{
Metabolically-active obligate aerobes in anoxic (sulfidic) marine sediments
}

Sabyasachi Bhattacharya ${ }^{1}$, Chayan Roy ${ }^{1}$, Subhrangshu Mandal ${ }^{1}$, Moidu Jameela Rameez ${ }^{1}$, Jagannath Sarkar ${ }^{1}$, Svetlana Fernandes ${ }^{2}$, Tarunendu Mapder ${ }^{3, \neq}$, Masrure Alam ${ }^{1, \#}$, Rimi Roy ${ }^{1, \pi^{\prime}}$, Nibendu Mondal ${ }^{1}$, Prosenjit Pyne ${ }^{1}$, Prabir Kumar Haldar ${ }^{1}$, Aditya Peketi ${ }^{2}$, Ranadhir Chakraborty ${ }^{4}$, Aninda Mazumdar ${ }^{2 *}$ and Wriddhiman Ghosh ${ }^{1 *}$

1 Department of Microbiology, Bose Institute, P-1/12 CIT Scheme VIIM, Kolkata - 700054, India.

2 Gas Hydrate Research Group, Geological Oceanography, CSIR-National Institute of Oceanography, Dona Paula, Goa - 403004, India.

3 Department of Chemistry, Bose Institute, 93/1 APC Road, Kolkata - 700009, India.

4 Department of Biotechnology, University of North Bengal, Siliguri, West Bengal - 734013, India.
Present addresses: $¥$ ARC CoE for Mathematical and Statistical Frontiers, School of Mathematical Sciences, Queensland University of Technology, Brisbane, QLD 4000, Australia.
* Department of Biological Sciences, Aliah University, IIA/27 New Town, Kolkata - 700160, West Bengal, India.
₫ Department of Botany, Jagannath Kishore College, Purulia - 723101, West Bengal, India.

*Correspondence emails: wriman@jcbose.ac.in / maninda@nio.org

Running Title: Strictly-aerobic life in anoxic sediments

\section{Abstract}

Metabolically-active obligate aerobes are unheard-of in tightly-anoxic environments. Present culture-independent and culture-dependent investigations revealed aerobic microbial communities along two, 3-meter-long sediment-cores underlying the eastern Arabian Sea oxygen minimum zone, where high $\mathrm{H}_{2} \mathrm{~S}$ disallows $\mathrm{O}_{2}$ influx from the water-column. While genes for aerobic respiration by $a a_{3}-/ c b b_{3}$-type cytochrome- $c$ oxidases and cytochrome-bd ubiquinol oxidase, and aerobic oxidation of methane/ammonia/alcohols/thiosulfate/sulfite/organosulfurcompounds, were present across the cores, so were live aerobic, sulfur-chemolithoautotrophs and chemoorganoheterotrophs. The 8820-years-old, highly-sulfidic, methane-containing sediment-sample from $275 \mathrm{cmbsf}$ of $530 \mathrm{mbsl}$ yielded many such obligately-aerobic bacterialisolates that died upon anaerobic incubation with alternative electron-acceptors/fermentativesubstrates. Several metatranscriptomic reads from this sediment-sample matched aerobicrespiration-/oxidase-reaction-/transcription-/translation-/DNA-replication-/membrane-transport/cell-division-related genes of the obligately-aerobic isolates, thereby corroborating their active aerobic metabolic-status in situ. Metagenomic and metatranscriptomic detection of perchlorate/chlorate-reduction genes, plus anaerobic growth of an obligately-aerobic Halothiobacillus isolate in the presence of perchlorate and perchlorate-reducing-consortia, suggested that cryptic $\mathrm{O}_{2}$ produced by perchlorate-respirers could be sustaining obligately-aerobes in this environment. 
Geomicrobial dynamics of marine oxygen minimum zones (OMZs) have profound influence on oceanic biodiversity, productivity and fixed-nitrogen loss ${ }^{1}$. For the OMZs distributed across the global ocean, microbial community architectures of their anoxic sediments ${ }^{2,3}$ are less explored as compared to those of the hypoxic waters ${ }^{4,5}$. Whereas the water-columns of OMZs afford pM-nM $\mathrm{O}_{2}$, which is reportedly sufficient for successful maintenance of aerobic lifestyle ${ }^{5-13}$, their sediments have extremely shallow $\mathrm{O}_{2}$-penetration depth ${ }^{14}$ due to high flux of labile organic matter across the sea-bed leading to rapid consumption of $\mathrm{O}_{2}{ }^{(15)}$. As physicochemical considerations ruled out influx of $\mathrm{O}_{2}$ from the water column below a few centimeters of $\mathrm{OMZ}$ sea-floors ${ }^{14}$, potential ecology of aerobic microorganisms was never investigated in these anoxic sediments, despite the fact that plausible aerobic activities can have significant effects on the catabolic breakdown (remineralization) of the copious, labile organic matters that are sequestered in the sediments underlying hypoxic marine waters ${ }^{15,16}$.

Across the sediment-horizons of Arabian Sea, which harbors the thickest and one of the most intensely hypoxic marine $\mathrm{OMZ}^{17}$, maximum depth of $\mathrm{O}_{2}$ penetration reported is 1.6 centimeters below the sea floor (cmbsf) ${ }^{14}$. In a recent study based on eight $\sim 3-\mathrm{m}$-long gravitycores, collected on-board $R V$ Sindhu Sankalp (SSK42) from across a water-depth transect covering the entire vertical-expanse of the eastern Arabian Sea OMZ (ASOMZ) (Supplementary Figure 1), we had revealed that anaerobic processes of the carbon-sulfur cycle heighten in the sulfidic sediments underlying the center of the OMZ's vertical-expanse ${ }^{2}$. Here we explore the same SSK42-cores from the ASOMZ-center, namely SSK42/5 and SSK42/6 located at 580 and 530 meters below the sea-level (mbsl) respectively, for the potential ecology of aerobic bacteria. We used a "geochemistry - metagenomics - pure/mixed culture characterization - genomics metatranscriptomics" approach to investigate microbiome structure/function in this sedimenthorizon, where high concentrations of pore-water $\mathrm{H}_{2} \mathrm{~S}^{(2)}$ preclude the presence/influx of free (gaseous/dissolved) $\mathrm{O}_{2}$, thereby making them ideal environments for exploring whether a functional ecology of aerobic bacteria is possible in a tightly anoxic environment.

\section{Results}

Geological context of the sample-site. Radiocarbon $\left({ }^{14} \mathrm{C}\right)$-based geological ages of the samples collected along SSK42/5 and 6 were found to range approximately between 1,00012,000 and 4,000-10,600 yr BP respectively. Sedimentation has occurred in this region at rates ranging between 11-132 $\mathrm{cm} \mathrm{ky}^{-1}$, without any apparent slumping or age reversal (Fig. 1a, e). Total organic carbon (TOC) content along SSK42/5 and 6 ranges between 1.2-4.6 and 0.5-3.7 wt $\%$ respectively $^{2}$ (Fig. 1b, f). TOC content along either core does not correlate with sedimentation rate, thereby discounting down-depth dilution as a plausible reason for decrease in TOC content 
along SSK42/5 or 6; instead, the latter is attributable to temporal changes in TOC flux and/or organic matter degradation due to sulfate reduction ${ }^{2}$. None of the cores showed any visible sign of bioturbation. $\mathrm{H}_{2} \mathrm{~S}$, along SSK42/5, has a maxima of $427 \mu \mathrm{M}$ at $105 \mathrm{cmbsf}$; in SS42/6, it increases with sediment-depth and reaches a maxima of $2010 \mu \mathrm{M}$ at $250 \mathrm{cmbsf}^{(2)}$ (see also Fig. 1c, g). Albeit technical limitations disallowed measurement of in situ $\mathrm{O}_{2}$ concentrations along SSK42/5 and 6 , theoretical considerations indicated that there is no possibility of any free $\mathrm{O}_{2}$ remaining in, or diffusing into, the chemical milieu where $\mathrm{H}_{2} \mathrm{~S}$ has already built-up, because the standing high-concentration of the strong reductant $\left(\mathrm{H}_{2} \mathrm{~S}\right)$ would have already reacted with the strong electron acceptor $\left(\mathrm{O}_{2}\right)$, either inorganically (following equation 1 ) or biochemically (following equations 2 and 3$)^{18}$. Close to the sediment-surface of SSK42/5 and 6, concentration of dissolved $\mathrm{O}_{2}$ in the sea-water is approximately $2 \mu \mathrm{M}$, as measured by a CTD profiler ${ }^{2}$. This implied that a maximum of $2 \mu \mathrm{M} \mathrm{O}_{2}$ is available in situ for potential diffusion down the sediment pores, while the stoichiometries of the $\mathrm{O}_{2}-\mathrm{H}_{2} \mathrm{~S}$ reactions given in equations 1-3 indicate that 1-4 $\mu \mathrm{M}$ in situ $\mathrm{H}_{2} \mathrm{~S}$ would be sufficient to remove this $\mathrm{O}_{2}$ as it tries to diffuse down the sedimentpores. Notably, a build-up of 62 and $321 \mu \mathrm{M}$ pore-water $\mathrm{H}_{2} \mathrm{~S}$ was detected at 1 and $30 \mathrm{cmbsf}$ of SSK $42 / 5$ and 6 respectively (only 0 and $15 \mathrm{cmbsf}$ sediment-samples of SSK42/6 were found to be dissolved-sulfide-free), while deeper-down the two cores $\mathrm{H}_{2} \mathrm{~S}$-accumulation was even higher ${ }^{2}$. These $\mathrm{H}_{2} \mathrm{~S}$ concentrations are high enough to scavenge not only the $\mathrm{O}_{2}$ diffusing into the sediments from the water-column, but also that which may be formed from potential abiotic/biotic processes and released directly into the chemical milieu. It can, therefore, be safely assumed that there is no dissolved $\mathrm{O}_{2}$ in the pore-waters beyond a few cmbsf, and a few tens of cmbsf, along SSK42/5 and 6 respectively.

$$
\begin{array}{ll}
3 \mathrm{O}_{2}+2 \mathrm{H}_{2} \mathrm{~S} \rightarrow 2 \mathrm{H}_{2} \mathrm{O}+2 \mathrm{SO}_{2} & \text { equation 1 } \\
2 \mathrm{O}_{2}+\mathrm{H}_{2} \mathrm{~S} \rightarrow \mathrm{H}_{2} \mathrm{SO}_{4} & \text { equation 2 } \\
\mathrm{O}_{2}+2 \mathrm{H}_{2} \mathrm{~S} \rightarrow 2 \mathrm{~S}^{\circ}+2 \mathrm{H}_{2} \mathrm{O} & \text { equation 3 }
\end{array}
$$

\section{Genes governing $\mathrm{O}_{2}$-requiring metabolisms are abundant in the anoxic/sulfidic sediments}

of ASOMZ. Whole metagenome shotgun sequencing and analysis along the two cores revealed footprints of such metabolisms which cannot operate in the absence of $\mathrm{O}_{2}$. When the metagenomic sequence data obtained for each of the 25 distinct sediment-samples of SSK42/5 and 6 (Supplementary Tables 1,2) were assembled and annotated individually, all the 25 contigcollections obtained were found to contain genes for aerobic respiration by $a a_{3}$-type cytochrome $c$ oxidase $(\operatorname{cox} A B C D)$, cbb3-type cytochrome $c$ oxidase (ccoNOPQ) and/or cytochrome-bd ubiquinol oxidase (cydABX and appX) (Supplementary Table 3). 19 out of the 25 contigcollections were found to contain genes for aerobic oxidation of methane/ammonia/alcohols [these included genes encoding particulate methane monooxygenase ( $m$ mo $A B C$ ), soluble 
methane monooxygenase $(m \operatorname{moX} Y Z B C D)$, methanol dehydrogenase ( $m x a F I)$ and/or alcohol oxidase (mox)] (Supplementary Table 4), whereas all 25 contained genes for the aerobic oxidation of thiosulfate (soxC for sulfane dehydrogenase), sulfite (SUOX for sulfite:acceptor oxidoreductase) and/or various organosulfur compounds (dmoA for dimethyl-sulfide monooxygenase, ssuD for alkanesulfonate monooxygenase, sfnG for dimethylsulfone monooxygenase and mtoX for methanethiol oxidase) (Supplementary Table 5).

In order to explore whether genes known to be involved in $\mathrm{O}_{2}$-dependent metabolisms are also present in other sulfidic/anoxic sediment-horizons of the sea, similar analyses as those described above were performed upon the $\mathrm{H}_{2} \mathrm{~S}$-containing sediment-samples of another 255-cmlong core, SSK42/9 (Supplementary Table 6). This comparator core was collected, during the same research cruise SSK42, from a shallower water-depth $(31 \mathrm{mbsl})$ located outside the perennial ASOMZ (Supplementary Figure 1), $\sim 128 \mathrm{~km}$ away from SSK42/5 and 6 . When the metagenomic sequence data obtained from 10 discrete sediment-samples of SSK42/9 (Supplementary Table 6) were individually assembled and annotated, eight out of the 10 contigcollections were found to contain genes for aerobic respiration by the above mentioned low- and high- $\mathrm{O}_{2}$-affinity cytochrome oxidases (Supplementary Table 7). Four and five contig-collections from SSK42/9 also encompassed genes for aerobic oxidation of methane/ammonia/alcohols (Supplementary Table 8) and thiosulfate/sulfite/organosulfur-compounds (Supplementary Table 9) respectively. These data indicated that the phenomenon of aerobic metabolisms in sulfidic/anoxic sediments could be widespread in the marine realm.

\section{Enrichment, isolation and characterization of obligately aerobic bacterial strains from} ASOMZ sediment. From the 275 cmbsf sediment-sample of SSK42/6 (age: $8820.3 \mathrm{yr}$ BP), where $\sim 1200 \mu \mathrm{M}$ hydrogen sulfide and $\sim 950 \mu \mathrm{M}$ methane in the pore-waters ${ }^{2}$ (see also Fig. 1g, h) rule out the presence/influx of free $\mathrm{O}_{2}$ in the chemical milieu, aerobic microbial consortia could be successfully enriched in the following bacteriological media - (i) chemoorganoheterotrophic, Luria-Bertani (LB) broth, and Reasoner's 2A (R2A) broth; (ii) chemolithoautotrophic, artificial sea water supplemented with thiosulfate (ASWT); and (iii) mixotrophic, modified basal and mineral salts-thiosulfate-yeast extract (MSTY) broth, and ASWT-yeast extract (ASWTY) broth. Simultaneously, high "most probable numbers" (MPN) of aerobic chemoorganoheterotrophs and aerobic sulfur-chemolithoautotrophs (determined in LB and ASWT respectively) were revealed along SSK42/5 and 6 (Supplementary Tables 10-13), thereby indicating that the aerobic bacteria of ASOMZ sediments, whether obligate or facultative, are alive in situ. 27 bacterial strains were isolated aerobically from the above mentioned enrichments in ASWT, MSTY and ASWTY. Taxonomically, the isolates formed nine species-level clusters, of which seven were classified under distinct genera while two clusters isolated separately in MSTY and ASWTY represented 
two distinct species of Halomonas (Table 1). One representative strain from each cluster was tested for anaerobic growth in its specific medium supplemented with the electron acceptors $\mathrm{NaNO}_{3}, \mathrm{Fe}_{2} \mathrm{O}_{3}, \mathrm{MnO}_{2}, \mathrm{Na}_{2} \mathrm{SO}_{4},\left(\mathrm{CH}_{3}\right)_{2} \mathrm{SO}$ and $\left(\mathrm{CH}_{3}\right)_{3} \mathrm{NO}$, which are all known to act as respiratory substrates in biogeochemically diverse marine microbiomes ${ }^{19-21}$. Subsequently, all the representative strains were also tested for anaerobic growth in their specific media supplemented with each of the above six electron acceptors separately. Furthermore, since many facultatively anaerobic or fermenting bacteria incapable of direct ferric iron reduction are known to channel their electrons towards iron reduction via external acceptors such as humic acids (this complex molecular mechanisms is called extracellular electron transfer) ${ }^{22,23}$, each of the current isolates were tested for anaerobic growth in their specific media supplemented with humic acids, or humic acids and $\mathrm{Fe}_{2} \mathrm{O}_{3}$ in combination. Aerobically incubated versions of all the above cultures exhibited cellular growth yields comparable with those obtained during aerobic growth in the same media-types minus any anaerobic respiratory substrate (Supplementary Table 14). This showed that the above mentioned electron acceptors or their used concentrations were non-toxic for the new isolates.

After 10 days of anaerobic incubation in their specific media supplemented with $\mathrm{NaNO}_{3}$, $\mathrm{Fe}_{2} \mathrm{O}_{3}, \mathrm{MnO}_{2}, \mathrm{Na}_{2} \mathrm{SO}_{4},\left(\mathrm{CH}_{3}\right)_{2} \mathrm{SO}$ and $\left(\mathrm{CH}_{3}\right)_{3} \mathrm{NO}$, the three representative strains MSTY-isolatedHalomonas SBBP1, Pusillimonas ginsengisoli MTCC 12559 and Stenotrophomonas sp. SBPC3 exhibited growth (Table 1). These three strains could also grow anaerobically in their respective media when $\mathrm{NaNO}_{3}$, but not the other five compounds, were provided individually as the sole electron acceptor - their cellular growth yields in the presence of $\mathrm{NaNO}_{3}$ were identical to those obtained in the presence of the six-electron-acceptor mixture (Supplementary Table 15). In contrast to the above three strains, after 10 days of anaerobic incubation in their specific media containing the six-electron-acceptor mixture, the representative Halothiobacillus strain SB14A retained only $4.6 \%$ of the initial cell count whereas the representative strains of the Cereibacter, ASWTY-isolated-Halomonas, Methylophaga, Pseudomonas and Sulfitobacter clusters had no viable cells left (Table 1). Use of the six individual electron acceptors separately in six different culture sets did not also help any of these strains to grow anaerobically (Supplementary Table 15). These results were consistent with the fact that no genetic system for respiration using nitrate, ferric, manganic or sulfate ion, or dimethyl sulfoxide or trimethylamine $\mathrm{N}$-oxide, were detected when the de novo sequenced and annotated genomes of these representative strains, namely Halothiobacillus sp. SB14A, Cereibacter changlaensis MTCC 12557, ASWTY-isolated Halomonas sp. MCC 3301, Methylophaga sp. MTCC 12599, Pseudomonas bauzanensis MTCC 12600 and Sulfitobacter sp. MCC 3606 were scrutinized manually as well as using the KEGG (Kyoto Encyclopedia of Genes and Genomes) Mapper - Reconstruct Pathway tool hosted by Kanehisa Laboratories at https://www.genome.jp/kegg/tool/map_pathway.html. 
After 10 days of anaerobic incubation in their specific media supplemented with humic acids, or humic acids and $\mathrm{Fe}_{2} \mathrm{O}_{3}$ in combination, neither the three strains that were characterized above as facultative anaerobes, nor those six which were found to be obligate aerobes, had any viable cell left in the cultures (Supplementary Table 15). Consistent with these findings, none of the key genes related to extracellular electron transfer (e.g., those encoding surface proteins such as Сyc2, a monoheme cytochrome $c$, and multiheme $c$-type cytochromes; porin-cytochrome $c$ protein complexes in which multiheme $c$-type cytochromes are secreted to the periplasm and embedded into a porin on the outer membrane to form the extracellular electron transfer conduit $^{23}$ ) were detected upon manual as well as KEGG Mapper - Reconstruct Pathway-based scrutiny of the annotated genomes of the six obligately aerobic isolates.

When the Cereibacter, ASWTY-isolated-Halomonas, Pseudomonas and Sulfitobacter strains were tested for fermentative growth/survival in their specified media supplemented with pyruvate, none, except the Pseudomonas strain, had any viable cell left after 5 days of anaerobic incubation. The Pseudomonas strain too had no viable cell left after 45 days. Fermentative survival of the Methylophaga strain was tested in ASW-methanol-fructose ${ }^{24}$, and that of the Halothiobacillus strain in ASWT [known strains of Halothiobacillus cannot utilize organic carbon, so this was to test survival via fermentation of stored polyglucose ${ }^{25}$ ] - the two strains had no viable cells left after 15 and 100 days respectively (Table 1). Corroborative to these data, genomes of the six obligately aerobic strains encompssed no gene encoding for the enzymes (such as lactate dehydrogenase, pyruvate:ferredoxin oxidoreductase, NADH: ferredoxin oxidoreductase, ferredoxin dehydrogenase, phosphotranscetylase, acetate kinase, acetaldehyde dehydrogenase, and acetyly-coA acetyl transferase) that are required for transformations of pyruvate to glycolytic fermentations.

De novo sequencing and analysis of the genomes of the obligately aerobic isolates. Whole genome shotgun sequencing, assembly and annotation were carried out for the six obligately aerobic isolates Cereibacter changlaensis MTCC 12557, Halomonas sp. MCC 3301, Halothiobacillus sp. SB14A, Methylophaga sp. MTCC 12599, Pseudomonas bauzanensis MTCC 12600 and Sulfitobacter sp. MCC 3606 (GenBank accession numbers are given in Table 1; general features of the assembled genomes given in Supplementary Table 16). All the six genomes were found to contain several oxidase-encoding genes, including those for $c b b_{3}$-type cytochrome c oxidase. All except Methylophaga sp. MTCC 12599 contained aa -type cytochrome $c$ oxidase genes, while all except Halothiobacillus sp. SB14A had genes for cytochrome-bd ubiquinol oxidase (see Supplementary Tables 17-22 in the alphabetical order of the six isolates).

Significant prevalence of all the six obligately-aerobic strains was evident across the $\mathrm{OMZ}$ sediment-horizon when substantial percentages of the metagenomic reads available for the 
individual sample-sites of SSK42/5 and 6 mapped onto each of the six newly-sequenced genomes (Fig. 2; Supplementary Table 16). In SSK42/5 and 6, approximately 0.01-0.3\% and 0.04-19.05\% metagenomic reads from the individual sample-sites mapped onto the six different genomes respectively; the only metagenome-genome pair to have no matching sequence was "45 cmbsf of SSK42/6 and Cereibacter changlaensis MTCC 12557". Prevalence of reads matching the six new isolates was relatively higher for the metagenomes of SSK42/6 (Fig. 2), and then within this core, highest for $275 \mathrm{cmbsf}$, the sample-site from where the strains were isolated (Supplementary Table 16). Furthermore, in this context, it is noteworthy that much higher proportions (0.6-1.0\%) of metagenomic reads from the $0-115 \mathrm{cmbsf}$ sample-sites of the comparator, $\mathrm{H}_{2} \mathrm{~S}$-containing sediment-core SSK42/9 mapped onto each of the six assembled genomes, as compared to the corresponding values for entire SSK42/5. Below $115 \mathrm{cmbsf}$ of SSK42/9, however, metagenomic reads matching these genomes were almost absent (0.010.05\% metagenomic reads from the $125-255 \mathrm{cmbsf}$ sample-sites of SSK42/9 mapped onto the six individual genomes; see Fig. 2; Supplementary Table 16).

Correspondence between genomic sequences of the obligately aerobic isolates and metatranscriptomic sequences from their habitat reflects in situ aerobic activity. The six bacterial isolates which not only failed to grow but also died within a few days/months of anaerobic incubation (despite being provided with alternative electron acceptors or fermentative substrates; see Table 1), could not have remained alive for thousands of years in their natural habitat without respiring $\mathrm{O}_{2}$, whatever may be its source and concentration in situ. There may well be a debate regarding which of the three metabolic states broadly referred to as living (namely dormant; active but not growing; and active and growing) ${ }^{26}$ did these strains exist in, for thousands of years in the ASOMZ sediment. In any case, it is for certain that none of the three states of life could have been achieved without some level of metabolic activity (to support basic cell maintenance, activity and/or growth) ${ }^{27-29}$, and any metabolic activity in an obligate aerobe ought to eventually involve aerobic respiration. However, since in situ aerobic metabolism is counterintuitive to the physicochemical conditions prevailing in the habitat (Fig. 1), we considered it imperative to test whether the native metatranscriptome of the sediment-sample from where the obligately aerobic strains were isolated contained transcripts corresponding to the aerobic metabolism-related genes of those strains. Furthermore, previous comparative analysis of totalmRNA sequence data from ecologically diverse microbial communities had identified that transcripts corresponding to core metabolic genes such as those associated with carbohydrate and energy metabolism, amino acid metabolism, nucleotide metabolism, protein translocation and cell division, are present in all metatranscriptomes ${ }^{30}$. Presence of such mRNAs were not only considered to be the quality/coverage benchmarks of the metatranscriptomic datasets, but also 
regarded as markers of in situ metabolic activity of the source bacteria ${ }^{30}$. We, therefore, additionally tested whether the native metatranscriptome from $275 \mathrm{cmbsf}$ of SSK42/6 contained mRNA sequences corresponding to these metabolic-activity markers of the obligately aerobic isolates.

Whole metatranscriptome of the $275 \mathrm{cmbsf}$ sediment-sample of SSK42/6 was sequenced, and the paired end mRNA reads obtained were mapped onto the manually-curated aerobicmetabolism-related gene-catalogs of the six obligately aerobic strains (Supplementary Tables 1722). Maximum number of metatranscriptomic read-pairs mapped onto the aerobic-metabolism gene-catalog of Halothiobacillus sp. SB14A, with a total 7492 read-pairs (i.e., $0.03 \%$ of the total 26,496,769 read-pairs examined) concordantly matching genes for aaz-type cytochrome $c$ oxidase, $c b b_{3}$-type cytochrome oxidase, and various other oxidase enzymes that, as a group, are all characterized by the catalysis of redox reactions involving $\mathrm{O}_{2}$ as the electron acceptor (Supplementary Table 19). For C. changlaensis MTCC 12557 (Supplementary Table 17), Halomonas sp. MCC 3301 (Supplementary Tables 18), P. bauzanensis MTCC 12600 (Supplementary Table 21) and Sulfitobacter sp. MCC 3606 (Supplementary Table 22), metatranscriptomic read-pairs matched concordantly with their genes for $a_{3}$-type cytochrome $c$ oxidase, $c b b_{3}$-type cytochrome oxidase, cytochrome-bd ubiquinol oxidase, as well as various other oxidases - total number of read-pairs mapping onto the aerobic-metabolism-related genecatalogs of these four strains were $665,2327,4845$ and 188 respectively (these numbers were $0.003,0.009,0.02$ and 0.0007 percent of the total 26,496,769 read-pairs tested). For Methylophaga sp. MTCC 12599, only 13 metatranscriptomic read-pairs (which was only $0.00005 \%$ of the total read-pairs tested) matched concordantly with its gene for cytochrome-bd ubiquinol oxidase subunit II (Supplementary Table 20).

Whether the six obligately aerobic strains were metabolically active in situ was further corroborated by mapping the metatranscriptomic reads obtained from the $275 \mathrm{cmbsf}$ sedimentsample of SSK42/6 onto their gene-catalogs pertaining to the metabolic categories (i) Genetic Information Processing (Transcription: RNA polymerase, Translation: Ribosome and Aminoacyl-tRNA biosynthesis, Replication and repair. DNA replication); (ii) Environmental Information Processing (Membrane transport. ABC transporters, Phosphotransferase system

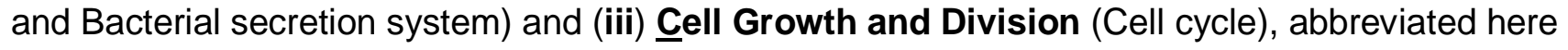
onwards as GEC gene catalogs. Of the six obligately aerobic isolates, Halothiobacillus sp. SB14A had the maximum number (221749) of metatranscriptomic read-pairs (i.e., $0.84 \%$ of the total 26,496,769 read-pairs tested) matching concordantly with 181 genes of its 183-gene strong GEC catalog (Supplementary Table 23). For C. changlaensis MTCC 12557 (Supplementary Table 24), Halomonas sp. MCC 3301 (Supplementary Table 25), P. bauzanensis MTCC 12600 (Supplementary Table 26) and Sulfitobacter sp. MCC 3606 (Supplementary Table 27), 22415, 
247934, 291711 and 33863 metatranscriptomic read-pairs (i.e., 0.09, 0.94, 1.10 and $0.13 \%$ of the total 26,496,769 read-pairs examined) matched concordantly with 245, 132, 147 and 133 genes of their 397-, 273-, 252- and 310-gene strong GEC catalogs. For Methylophaga sp. MTCC 12599 , only 7327 metatranscriptomic read-pairs (which was only $0.03 \%$ of the total read-pairs examined) matched concordantly with 34 genes of its 193-gene strong GEC catalog (Supplementary Table 28).

Perchlorate-/chlorate-respiring bacteria as a potent source of $\mathrm{O}_{2}$ for aerobic bacteria in

ASOMZ sediments. In view of the absence of free $\mathrm{O}_{2}$ in the sulfidic chemical milieu of SSK42/5 and 6 , it was imperative to explore the potential source(s) of cryptic $\mathrm{O}_{2}$ that may be facilitating aerobic life in situ. Perchlorate/chlorate disproportionation ${ }^{31}$ is a microbial metabolic process that can potentially serve this purpose. Perchlorate $\left(\mathrm{ClO}_{4}^{-}\right)$and chlorate $\left(\mathrm{ClO}_{3}^{-}\right)$respiring bacteria disproportionate the highly oxidized states of chlorine to chloride $\left(\mathrm{Cl}^{-}\right)$and $\mathrm{O}_{2}$ by the consecutive actions of (per)chlorate reductase (that catalyzes the reduction of perchlorate to chlorite via chlorate) and chlorite dismutase (that converts chlorite to chloride and oxygen) ${ }^{31}$. Remarkably, several genes encoding (per)chlorate reductase and/or chlorite dismutase were identified within the metagenome assemblies carried out for all the individual sediment-samples of SSK42/5 and 6, except 220 and 250 cmbsf of SSK42/6 (Supplementary Table 29). We, therefore, hypothesized that potentially-close association with these oxygenic anaerobes could be one of the means by which aerobic lifestyle is sustained in the ASOMZ sediments. Furthermore, when the metagenomic sequence data obtained from the 10 discrete sediment-samples of SSK42/9 were individually assembled and annotated, 8 out of 10 contig-collections obtained were also found to contain (per)chlorate reductase genes (Supplementary Table 30).

Guided by the above hypothesis, perchlorate-respiring bacterial consortia (PRBC) could be successfully enriched in perchlorate-supplemented, basal bicarbonate-buffered (PBBB) medium by anaerobically incubating (at $15^{\circ} \mathrm{C}$ for 45 days) different sediment-samples of SSK42/5 and 6. Following another round of 7 day sub-culturing, enrichments corresponding to 120 and $260 \mathrm{cmbsf}$ of SSK42/5, and 135 and $275 \mathrm{cmbsf}$ of SSK42/6, produced maximum $\mathrm{O}_{2}$ and/or biomass; so these PRBC were selected for individual anaerobic co-culture experiments with the obligately aerobic isolate Halothiobacillus SB14A in a PBBB-ASWT consensus medium containing energy/electron/carbon sources suitable for both biotypes, but only $\mathrm{ClO}_{4}^{-}$, and no $\mathrm{O}_{2}$, as electron acceptor. After 60 days of anaerobic incubation in the consensus medium, SB14A, when accompanied by a PRBC, exhibited 1.1-22 fold increases in viable-cell count (in the different co-culture sets, increases in viable-cell count of Halothiobacillus SB14A varied because the different $\mathrm{O}_{2}$-providing, undefined-consortia that were used contained differential diversities and abundances of perchlorate-respirers; this caused $\mathrm{O}_{2}$-availability, and therefore 
Halothiobacillus growth, to vary). In contrast, when SB14A was incubated anaerobically in the same medium, but in the absence of any PRBC, the culture lost $99.6 \%$ of the initial cell count (Supplementary Table 31). Furthermore, after 60 days of anaerobic incubation in a perchlorateless variant of the consensus medium, SB14A cultures, whether accompanied by a PRBC or not, lost 99.6-99.7\% of the initial cell counts (Supplementary Table 31). These results corroborated the feasibility of obligate aerobes surviving in anoxic habitats by means of potentially close associations with oxygenic, perchlorate-respiring bacteria.

No $\mathrm{ClO}_{4}{ }^{-}$was detected in the pore-water of any sediment-depth explored along SSK42/5, 6 or 9 using ion chromatographic method that apparently had a detection limit of $10 \mu \mathrm{M}(1 \mathrm{ppm})$. However, potentially functionality of perchlorate respiration in these sediments was suggested by the detection of (per)chlorate reductase homologs in the gene-catalog obtained via assembly and annotation of the metatranscriptomic sequence dataset obtained from $275 \mathrm{cmbsf}$ of SSK42/6 (Supplementary Table 32). Presence of no chlorite dismutase homolog in the assembledmetatranscriptome-derived gene-catalog, or for that matter presence of relatively less number of homologs for chlorite dismutase than (per)chlorate reductase in the assembled-metagenomederived gene-catalogs, could be reflective of the in situ prevalence of novel molecular diversities of chlorite dismutase genes which did not get detected in automated annotation procedures. This supposition is consistent with the fact that de novo sequencing and automated annotation of the genomes of perchlorate-respiring bacterial strains isolated subsequently from $275 \mathrm{cmbsf}$ of SSK42/6 also revealed no chlorite dismutase homolog (Unpublished data of this research group).

\section{Discussion}

In contemporary biogeochemical explorations of marine $\mathrm{OMZ}$ waters, $<3 \mathrm{nM}$ dissolved $\mathrm{O}_{2}$ has been regarded as anoxic due to the limitations of field-applicable $\mathrm{O}_{2}$-detection technologies ${ }^{4,7,13}$. It is, however amply illustrated in the literature that the low levels of dissolved $\mathrm{O}_{2}$ present in $\mathrm{OMZ}$ waters are not only supportive of in situ aerobic metabolisms $s^{5,8,10,12,13}$ but also reasonably within the known frontiers of minimum- $\mathrm{O}_{2}$ necessary for aerobic microbial life ${ }^{9,11}$. By contrast, the $\mathrm{H}_{2} \mathrm{~S}-$ rich sediments underlying the center of the vertical expanse of the eastern ASOMZ are far more tightly anoxic. Revelation of live and metabolically active aerobic microorganisms in such an environment, therefore, opens up a new frontier in understanding Life's opportunities and adaptations in the extremes.

Results obtained from the metatranscriptomic read mapping experiments showed that the obligately aerobic strains, in their native habitat, were not only metabolically active and respiring with $\mathrm{O}_{2}$, but were also growing/replicating in all likelihood. Inferring metabolic activity from transcript profiles is justified not only since mRNAs effect all metabolic functions and fluxes 
through their translation into enzymes and transporters, but also because, in the light of evolutionary optimality ${ }^{32}$, it is axiomatic that if a cell undertakes mRNA production it does so only to effect the function in which the coded protein is involved. As for environmental metatranscriptomes, instantaneous inventories of mRNA pools are considered to be highly informative about ecologically-relevant processes (community functions) going on in situ ${ }^{33}$, while annotation of total environmental mRNAs with reference to specific genome sequences are adept to revealing the active biochemical functions of particular microorganisms within a community ${ }^{30}$. mRNAs in eukaryotic and bacterial cells have half-lives in the order of hours to days, and only a few minutes to hours, respectively ${ }^{34,35}$. In bacteria, mRNA half-lives average between 1 and $8 \square \min$, for both laboratory-grown and environmental cells, independent of their growth rates ${ }^{33,35}$; for some extremophilic archaea, transcript stabilities are a bit higher and range between 5 and $>18 \mathrm{~min}^{36}$. For marine bacterial isolates, half-life time of mRNA transcripts have been found to range between 1 and $46 \mathrm{~min}$, while for coastal metatranscriptomes it ranges from 9 to $400 \mathrm{~min}^{37}$. Notably, mRNAs do not form secondary structures as tRNAs and rRNAs do, and therefore they are far more unstable than the latter types of RNA. This may the reason why rRNAs from some eukaryotic organisms have been found to remain stable over geological time periods, in cellular as well as extracellular milieus, across marine subsurface provinces ${ }^{38}$, whereas there is not a single report of long-term preservation of any prokaryotic mRNA in geological samples. Bacteria in various coastal environments, freshwaters, soils, and sediments have an average mRNA content of only 200-300 molecules per cell, and each of these last for only a few minutes before being degraded ${ }^{33}$; this allows the metabolic state of a cell to adjust to changing environmental conditions via alteration of its expressing gene-set ${ }^{36}$. Consequently, in an environmental sample, it is impossible to obtain mRNA transcripts of a bacterium (especially those corresponding to core metabolic activities such as transcription, translation, DNA replication, membrane transport and cell cycle) in case of its in situ dormancy or cell-system collapse (death). As for the $15-25^{\circ} \mathrm{C}$ sediments of SSK42/5 and 6, which are characterized by high in situ organic carbon content and hectic carbon-sulfur cycling ${ }^{2}$, we hypothesize, based on all the above considerations, that longevity of bacterial mRNA, in case of dormancy or cell death, could be in the order of few minutes. This supposition is corroborated by the reported identification of very low amount of mRNA in dormant laboratory cultures of Mycobacterium tuberculosis ${ }^{39}$, and revelation of strong positive correlation between the abundance of bacterial mRNAs involved in cell division and in situ concentration of bacterial cells cell, during the metatranscriptomic exploration of anaerobic Peru Margin sediments ${ }^{40}$. Notably, metatranscriptome analysis has also been used to delineate active prokaryotic community functions in $\mathrm{O}_{2}$-depleted sediments of Baltic Sea that are biogeochemically comparable with the ASOMZ sediments ${ }^{41}$. 
Based on the data obtained in this study, the role of perchlorate-/chlorate-respiration as a cryptic source(s) of $\mathrm{O}_{2}$ for aerobic life in the anoxic sediments of $A S O M Z$ is at best hypothetical. The bases of origin, concentration-levels, distribution, and bioavailability of $\mathrm{ClO}_{4}{ }^{-}$(which is thus far appreciated mainly as a chemical of anthropogenic origin ${ }^{42}$ ) in the marine realm is completely unknown, and requires substantiation by new studies of biogeochemistry. Whilst there is every possibility of other biotic/abiotic contrivances being there in the ASOMZ sediment ecosystem to meet the $\mathrm{O}_{2}$ requirement of strictly aerobic life, and/or to take care of the electron load of the obligate aerobes living in situ, in the current context, it is noteworthy that a number of previous studies have reported the isolation of perchlorate-/chlorate-respiring bacterial strains (endowed with all genetic components necessary for perchlorate reduction) from marine sediment-samples that, like SSK42/5 and 6, also did not contain detectable perchlorate ${ }^{43-45}$. Furthermore, from a purely microbiological point of view, close symbiotic association of perchlorate-reducers with aerobic microorganisms (that can scavenge $\mathrm{O}_{2}$ for them) makes ecophysiological sense in the context of the anoxic ASOMZ sediments. Perchlorate-reducers respire $\mathrm{O}_{2}$ (and sometimes nitrate) in preference over perchlorate, and for some of them 2-6 $\mathrm{mg} \mathrm{L}^{-1} \mathrm{O}_{2}$ inhibits perchlorate reduction irreversibly ${ }^{31}$. However, in redox-stratified unbioturbated sediments ${ }^{46}$ as those of SSK $42 / 5$ and $6^{(2)}, \mathrm{O}_{2}$ is consumed within the top few millimeters, and nitrate penetrates slightly deeper than that; consequently, perchlorate-respiration, and therefore a low- $\mathrm{O}_{2}$ microenvironment, apparently becomes mandatory for the in situ survival of these bacteria.

Whatever may be the source(s) of cryptic $\mathrm{O}_{2}$ in the sulfidic/anoxic sediments underlying the eastern Arabian Sea OMZ, metabolically active obligate aerobes in such territories (Fig. 2) hold potent implications for the in situ remineralization of organic matter and oxidation of sulfur, iron and nitrogen species. OMZs and similar hypoxic marine water bodies are characterized by high flux of labile organic matter across the sea-bed ${ }^{15,16}$, and bulk of this is likely to be complex in nature (i.e. comprising large number of carbon atoms) because low $\mathrm{O}_{2}$ in the water columns ${ }^{4,7,13}$, and zero $\mathrm{O}_{2}$ below a few centimeters from the sea-floor ${ }^{14}$, disallows large-scale aerobic degradation. For the sediments of SSK42/5 and 6 too, TOC content is copious, and anaerobic processes of the carbon-sulfur cycle (that are fuelled by simple carbon compounds such as acetate, lactate, formate, methanol, etc.) are highly active ${ }^{2}$. So it had thus far been a biogeochemical intrigue as to how the high demand for simple carbon compounds is satisfied in this kind of sedimentary ecosystems which are impinged by acutely hypoxic waters. Irrespective of whether the simple carbon compounds produced from the low levels of aerobic catabolism in the hypoxic waters/sediment-surfaces (together with those potentially formed within the sediment package from plausible anaerobic hydrolysis and fermentation) are enough for this purpose, the present discovery of metabolically active crypto-aerobic microflora within this anoxic sedimenthorizon clearly adds a whole new dimension to the scope and extent of in situ remineralization of 
sequestered organic carbon. By design, implications of this phenomenon are most likely to extend to carbon, sulfur, nitrogen and metals cycling in the benthic realm at large and plausibly also in other anoxic territories of the Earth's biosphere. New lines of concerted investigation of the ecology of crypto-aerobic microbial communities (via omics- as well as culture-based approaches) and their in situ geological interactions, manifestations and records are needed to gain comprehensive insights into the global biogeochemical significance of aerobic microbial life amidst anoxia.

\section{Methods}

Sample collection and storage. The gravity-cores SSK42/5, 6 and 9 were collected from 580

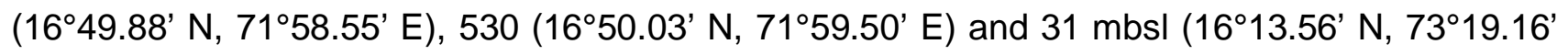
E) respectively, off the west coast of India, and sampled under constant shower of high-pure $\mathrm{N}_{2}$, as described previously ${ }^{2}$. Immediately after cutting and removing the longitudinal halves of the PVC core-liners, top one $\mathrm{cm}$ of the exposed surfaces were scrapped-off to avoid contaminations from the core-liner's inner surface and/or sea water; sampling was then carried out from the interiors. For every sediment-depth explored, two sample-fractions designated for duplicate total community DNA/RNA isolation were collected and put into $-20^{\circ} \mathrm{C}$ freezers, while one samplefraction each for culture-based microbiology and chemistry were kept at $4^{\circ} \mathrm{C}$. Before refrigeration, sample bottles were flushed with nitrogen gas, screw-capped, and sealed with Parafilm (Bemis Company Inc., USA). During transfer to the institute laboratories, and also over long-term sample-preservation, the above mentioned temperatures were maintained consistently. During investigation, sample-bottles meant for chemistry or culture-independent microbiology were always opened aseptically under constant nitrogen flow; sample-bottles meant for culture-based microbiology were opened inside a Whitley H35 Hypoxystation (Don Whitley Scientific, UK) preset at $75 \%$ humidity and $0 \%$ partial pressure of $\mathrm{O}_{2}$ using the gas mixture $\mathrm{N}_{2}: \mathrm{H}_{2}: \mathrm{CO}_{2}=$ 80:10:10 (v/v/v). After every use, sample-bottles were screw-capped and sealed with fresh Parafilm.

Age of the samples and sedimentation rate. Radiocarbon $\left({ }^{14} \mathrm{C}\right)$ dates were determined on bulk planktonic foraminifera. An assemblage of 200 specimens was cleaned ultrasonically in sodium hexametaphosphate solution and $\mathrm{H}_{2} \mathrm{O}_{2}(30 \%)$ in order to remove any adhered clay particles and organic carbon respectively. After the specimens were rinsed with distilled water, Foraminifera tests were further broken to remove fragments bearing pyrite, quartz and authigenic carbonates as much as possible. ${ }^{14} \mathrm{C}$ dates were determined using accelerator mass spectrometry (AMS) at the National Ocean Sciences AMS Facility of Woods Hole Oceanographic Institution, Woods 
Hole, MA, USA. Carbon dioxide generated from the dissolution of foraminifera shells in $\mathrm{H}_{3} \mathrm{PO}_{4}$ was reacted with catalyst to form graphite, which was then pressed into targets and analyzed on the accelerator along with standards and process blanks. NBS Oxalic Acid I (NIST-SRM-4990) and Oxalic Acid II (NIST-SRM-4990C) were used as the primary standards during ${ }^{14} \mathrm{C}$ measurements ${ }^{47}$. Radiocarbon ages were converted to mean calendar ages using the calibration curve of Fairbanks et al. (2005) ${ }^{48}$. Ages were expressed as radiocarbon years before 1950 AD, or years before present (yr BP), using the Libby half-life of 5568 years. 400 years were used as reservoir age for calibration ${ }^{49}$.

Extraction of total DNA/RNA from sediment-samples/microbial cultures. Total community DNA was extracted from native sediment-samples using PowerSoil DNA Isolation Kit (MoBio, USA) as per the manufacturer's protocol. Microgram-levels of DNA were obtained from each preparatory reaction that started with $0.5 \mathrm{~g}$ sediment-sample. Genomic DNA of the pure culture isolates was extracted using HiPurA Bacterial Genomic DNA Purification Kit (Himedia, India), following manufacturer's instructions. Total community RNA was extracted from the $275 \mathrm{cmbsf}$ sediment-sample of SSK42/6 using the RNA PowerSoil Total RNA Isolation Kit (MoBio), as per manufacturer's protocol. Nanogram-level total RNA was obtained after pooling up the products of 15 individual preparatory reactions, each carried out using $2 \mathrm{~g}$ sediment-sample.

Sequencing of metagenomes/genomes/metatranscriptomes. The duplicate metagenomes isolated for each sediment-depth explored along SSK42/5, 6 and 9 were shotgun sequenced individually on an Ion Proton sequencing platform (Thermo Fisher Scientific, USA) using 200 nucleotide read-chemistry, as described previously ${ }^{50}$ (details given in Supplementary Methods; complete lists of sedimentary communities investigated along SSK42/5, 6 and 9 are given in Supplementary Tables 1, 2 and 6 respectively). Whole genomes of the pure culture isolates were shotgun sequenced on an lon S5 platform (Thermo Fisher Scientific) using 400 nucleotide readchemistry (details given in Supplementary Methods). The total community RNA extracted from the $275 \mathrm{cmbsf}$ sediment-sample of SSK42/6 was sequenced on a HiSeq4000 platform (Illumina Inc., USA) using paired end, $2 \times 150$ nucleotide, sequencing by synthesis read-chemistry with dual indexing workflows. Details of sequencing-library preparation are given in Supplementary Methods. Depletion of rRNAs was carried out using Ribo-Zero Gold (Illumina), which is an integral part of the TruSeq Stranded mRNA and Total RNA kit (Illumina) used for preparing the library. Very little rRNA escaped the Ribo-Zero treatment where, according to the kit manual, biotinylated probes bind rRNA species selectively, and magnetic beads capture and pull-down the probe-rRNA hybrids, leaving the desired rRNA-depleted RNA pool in solution. In order to extract and eliminate whatever rRNA reads were there in the raw metatranscriptomic sequence 
dataset, the 26,579,343 read-pairs available in all were mapped onto SILVA large subunit as well as small subunit rRNA gene sequence database ${ }^{51}$, using the short read aligner Bowtie 2 v.2.3.4.3 $3^{(52)}$ in default local (sensitive) alignment mode; this identified only $\sim 0.3 \%$ metatranscriptomic reads as ascribable to rRNAs, thereby leaving 26,496,769 read-pairs in the rRNA-sequence-free final dataset used for downstream analyses (notably 20 million reads has been proven reasonably sufficient for enzyme discovery in any microbiome in general) ${ }^{30}$.

De novo assembly and annotation of metagenomes/genomes/metatranscriptome. All sequence datasets were quality-filtered with Phred score cut-off 20 using Fastx_toolkit 0.0.13.2 (http://hannonlab.cshl.edu/fastx_toolkit/download.html). High quality reads from the duplicate metagenomic sequence datasets available for each sediment-community were co-assembled using Megahit v1.2. $x^{(53)}$ with the kmers 21, 29, 39, 59, 79, 99, 119 and 141 for a minimum contiglength of $100 \mathrm{bp}$; the assemblies were quality-checked by MetaQUAST ${ }^{54}$; >100-bp-long contigs were searched for ORFs/genes encoding >30-amino-acids-long peptides, using MetaGeneMark ${ }^{55}$.

For the genomes of pure-culture isolates, high quality reads were assembled using SPAdes 3.13.0 (56), with kmers 21, 33, 55, 77, 99 and 127, and minimum coverage cut-off 35X. Statistics for $>200$-bp-long contigs was generated from the assemblies using QUAST $^{57}$ and viewed using Bandage ${ }^{58}$; <200-bp-long contigs were filtered out from the final assemblies. The whole genome sequences were deposited to the GenBank and annotated using Prokaryotic Genome Annotation Pipeline located at https://www.ncbi.nlm.nih.gov/genome/annotation_prok/) of National Center for Biotechnology Information (NCBI), USA. Raw reads from the individual metagenomic or metatranscriptomic datasets were mapped onto the individual assembled whole genome sequences, or the manually-curated aerobic-metabolism-related gene-catalogs obtained from the individual genome annotations, using Bowtie2 v.2.3.4.3 ${ }^{(52)}$ in default local (sensitive) alignment mode.

The rRNA-sequence-free metatranscriptomic dataset was assembled using the python script rnaspades.py, available within SPAdes $3.13 .0^{(56)}$, with default parameters. ORFs/genes encoding continuous stretches of minimum 30 amino acids were predicted in contigs longer than 100 bp using Prodigal v2.6.3 ${ }^{(59)}$.

Gene-catalogs obtained from the individual metagenomes or the metatranscriptome were functionally annotated by searching against EggNOG v5.0 database (http://eggnog5.embl.de/download/eggnog_5.0/) with EggNOG-mapper (http://betaeggnogdb.embl.de/\#/app/emapper) using HMMER algorithm. Putative protein sequence catalogs obtained for the individual genomes via PGAP annotation were re-annotated by searching against EggNOG v5.0 database with EggNOG-mapper using HMMER algorithm. Enzymes 
involved in aerobic respiration, aerobic methane/sulfur oxidation and perchlorate reduction were screened manually on the basis of their KEGG Orthology numbers ${ }^{60}$.

549

550

551

552

553

554

555

556

557

558

559

560

561

562

563

564

565

566

567

568

569

570

571

572

573

574

575

576

577

578

579

580

581

582

MPN of aerobic chemoorganoheterotrophs/chemolithoautotrophs. MPN of viable cells of aerobic, chemoorganoheterotrophs and sulfur-chemolithoautotrophs in the individual sedimentsamples were calculated, as described previously ${ }^{61}$, using ten-fold dilution series (and three tubes per dilution) of aerobic slurry-cultures in LB ( $\mathrm{pH} 7.0)$ and ASWT ( $\mathrm{pH} 7.5)$ broths respectively (details given in Supplementary Methods). Growth responses observed in an MPNtube series were tallied with a standard MPN Table ${ }^{61}$ (www.jlindquist.net) to get the MPN of the corresponding metabolic-type $\mathrm{g}^{-1}$ sediment-sample.

Enrichment, isolation and identification of aerobic bacterial strains. To test the presence of viable aerobic microorganisms in ASOMZ sediment, microbial consortia were enriched aerobically from the $275 \mathrm{cmbsf}$ sample of SSK42/6 using the following broth media: LB, R2A (pH 7.0), ASWT, MSTY (pH 7.0) and ASWTY (pH 7.5). ASWT62 and ASWTY both contained $10 \mathrm{mM}$ $\mathrm{Na}_{2} \mathrm{~S}_{2} \mathrm{O}_{3} .5 \mathrm{H}_{2} \mathrm{O}$ while MSTY 63 contained $20 \mathrm{mM} \mathrm{Na}_{2} \mathrm{~S}_{2} \mathrm{O}_{3} .5 \mathrm{H}_{2} \mathrm{O}$; MSTY and ASWTY contained $500 \mathrm{mg}$ yeast extract $\mathrm{L}^{-1}$. Detailed compositions of all the five media are given in Supplementary Methods. $5 \%(\mathrm{w} / \mathrm{v})$ sediment-samples were added to the individual broth media contained in cotton-plugged conical flasks having 60\% headspaces filled with air; these flasks were incubated aerobically at $15^{\circ} \mathrm{C}$ on a rotary shaker (150 rpm). Turbidity of cultures and production of sulfuric acid from thiosulfate ${ }^{62,63}$ were taken as signs of microbial growth in LB/R2A and ASWT/MSTY/ASWTY respectively. After phenol red indicator present in the media turned yellow due to production of sulfuric acid from thiosulfate, aerobic bacterial strains were isolated from the enrichments in ASWT, MSTY and ASWTY, via serial dilution, spread-plating onto corresponding agar media, aerobic incubation at $15^{\circ} \mathrm{C}$, and then iterative dilution streaking till all colonies in an isolation plate looked similar ${ }^{63}$. Representative colonies from individual pure-plates were designated as strains and maintained in their respective isolation-media - only the Methylophaga strains, despite being isolated in ASWT, were maintained in ASW supplemented with 0.3\% (v/v) methanol (ASWM) because their growth vigor in ASWT waned after six consecutive sub-cultures. Strains were classified down to the lowest identifiable taxonomic category, as described previously ${ }^{63}$, on the basis of their $16 \mathrm{~S}$ rRNA gene sequence similarities with validly-published species (http://www.bacterio.net/).

Tests for anaerobic/fermentative growth/survival. Isolates were tested for anaerobic growth in their respective maintenance media (Table 1) supplemented with $\mathrm{NaNO}_{3}(4 \mathrm{mM})^{64}, \mathrm{Fe}_{2} \mathrm{O}_{3}(125$ $\mathrm{mM})^{65}, \mathrm{MnO}_{2}(1 \mathrm{mM})^{66}, \mathrm{Na}_{2} \mathrm{SO}_{4}(10 \mathrm{mM})^{67},\left(\mathrm{CH}_{3}\right)_{2} \mathrm{SO}(56 \mathrm{mM})^{68}$ and $\left(\mathrm{CH}_{3}\right)_{3} \mathrm{NO}(27 \mathrm{mM})^{68}$ as 
electron-acceptors, provided both as mixture of all six compounds or as single respiratory substrate. Isolates were also tested for anaerobic growth in their respective maintenance media supplemented with humic acids $\left(17 \mathrm{mg} \mathrm{mL}^{-1}\right)^{22}$, or humic acids $\left(17 \mathrm{mg} \mathrm{mL}^{-1}\right)$ and $\mathrm{Fe}_{2} \mathrm{O}_{3}(40 \mathrm{mM})$ in combination ${ }^{22}$. Isolates which died in these culture conditions were tested for fermentative growth/survival. The Cereibacter, ASWTY-isolated-Halomonas, Pseudomonas and Sulfitobacter isolates could not grow aerobically/anaerobically in fermentative medium generally used for lactobacilli69; so they were provided pyruvate $\left(5 \mathrm{~g} \mathrm{~L}^{-1}\right)$ as fermentative substrate. Since fructose is the only multicarbon compound utilized by known Methylophaga species ${ }^{24}$, the current isolate belonging to this genus was tested for fermentative growth in ASWM medium supplemented with $0.3 \%(\mathrm{w} / \mathrm{v})$ fructose. Under anaerobic condition all Halothiobacillus species lose their obligate sulfur-chemolithotrophic attributes and reportedly perform heterolactic fermentation of stored polyglucose ${ }^{25}$; the present Halothiobacillus isolate (SB14A), therefore, was subjected to prolonged incubation in ASWT to test the potential role of such processes in the anoxic survival of this strain.

All components of the above media were mixed, supplemented with $0.5 \mathrm{~g} \mathrm{~L}^{-1}$ sodium thioglycolate (to eliminate $\mathrm{O}_{2}$ ) and $0.1 \mathrm{mg} \mathrm{L}^{-1}$ resazurin (to indicate presence of $\mathrm{O}_{2}$ ), and then autoclaved in screw-capped bottles. Methanol was added via filter sterilization after the screwcapped bottles were opened inside the $\mathrm{H} 35$ Hypoxystation preset to zero $\mathrm{O}_{2}$. Likewise, phosphate, thiosulfate and pyruvate were dissolved in $\mathrm{O}_{2}$-free water, filter-sterilized, and added to the relevant media, inside the anaerobic workstation. $100 \mathrm{~mL}$ aliquots of individual $\mathrm{O}_{2}$-free testmedia were dispensed into narrow-mouth and fixed-joint Erlenmeyer flasks, following which cells harvested from $1 \mathrm{~mL}$ aerobically-grown mid-log phase seed cultures were added to them; finally the flasks were covered with sleeve stopper septa and incubated at $15^{\circ} \mathrm{C}$; all these steps were carried out within the anaerobic workstation. Viable cell count in an anaerobic/fermentative culture at desired time-points of incubation (including $0 \mathrm{~h}$ ) was determined by counting the colony forming units (CFU) present. To determine CFU-count, $1 \mathrm{~mL}$ of the liquid culture was taken out, its various dilution grades plated in triplicates onto agar plates of the corresponding medium (these were done inside the anaerobic workstation), and finally incubated aerobically (outside the workstation). Colony-counts in the different dilution-plates were multiplied by their dilution factors, summed-up, and averaged to get the CFU count $\mathrm{mL}^{-1}$ of the test-culture.

\section{Enrichment of perchlorate-respiring consortia (PRBC) and their co-culture with}

Halothiobacillus SB14A. $2 \mathrm{~g}$ each of the different sediment-samples were added (inside the $\mathrm{H} 35$ Hypoxystation preset at zero $\mathrm{O}_{2}$ ) to separate $40 \mathrm{~mL}$ batches of $\mathrm{O}_{2}$-free PBBB medium (pH 7.0; composition given in Supplementary Methods $)^{70}$ contained in fixed-joint Erlenmeyer flasks and supplemented with $0.5 \mathrm{~g} \mathrm{~L}^{-1}$ sodium thioglycolate and $0.1 \mathrm{mg} \mathrm{L}^{-1}$ resazurin. All the flasks 
were covered with sleeve stopper septa and incubated anaerobically at $15^{\circ} \mathrm{C}$ for 45 days, following which $5 \%$ inocula were transferred to fresh batches of $40 \mathrm{~mL}$ PBBB media. After 7 day incubation of the sub-cultures, the four enrichment sets which exhibited highest $\mathrm{O}_{2}$ and/or biomass production were selected for anaerobic co-culture with SB14A. Accordingly,from the 7day-old PRBC sub-cultures corresponding to 120 and $260 \mathrm{cmbsf}$ of SSK42/5, and 135 and 275 cmbsf of SSK42/6, 10\% inocula were added individually, alongside 1\% inoculum from a mid-log phase culture of Halothiobacillus SB14A, to $40 \mathrm{~mL}$ of an $\mathrm{O}_{2}$-free, PBBB-ASWT consensus medium ( $\mathrm{pH} \mathrm{7.0;} \mathrm{composition} \mathrm{given} \mathrm{in} \mathrm{Supplementary} \mathrm{Methods)} \mathrm{that} \mathrm{contained}$ energy/electron/carbon sources suitable for perchlorate-respirers as well as Halothiobacillus, but perchlorate as sole electron acceptor $\left(\mathrm{O}_{2}\right.$-containing version of this consensus medium was found to support aerobic growth of SB14A, thereby proving its non-toxicity towards this chemolithoautotroph; see Supplementary Table 31). The consensus medium with or without perchlorate was dispensed into $100 \mathrm{~mL}$ fixed-joint Erlenmeyer flasks, inoculated with washed cell pellets of both types of cultures or only SB14A harvested according to the inoculums percentages stated above, and covered with sleeve stopper septa inside the anaerobic workstation. The cultures were incubated anaerobically at $15^{\circ} \mathrm{C}$ for 60 days, and Halothiobacillus CFU present $\mathrm{mL}^{-1}$ determined, as stated above, at appropriate time-intervals (including $0 \mathrm{~h}$ ) by dilution plating in ASWT-agar followed by aerobic incubation at $15^{\circ} \mathrm{C}$. Three discrete colonies from each CFU-counting plate were checked by $16 \mathrm{~S}$ rRNA gene sequence analysis to corroborate their Halothiobacillus identity.

Analytical methods. To corroborate sulfur-chemolithotrophic/mixotrophic growth of purecultures/microbial consortia, concentrations of dissolved thiosulfate and sulfate in the spent media were measured by iodometric titration, and gravimetric precipitation with $\mathrm{BaCl}_{2}$, respectively ${ }^{64}$. Potential concentration of dissolved perchlorate in the sediment pore-waters were determined by ion chromatography using an Eco IC (Metrohm AG, Switzerland) equipped with a conductivity detector (Metrohm, IC detector 1.850.9010). Chemical suppression was used for this purpose, while separation was carried using a Metrosep A Supp5 - 250/4.0 (6.1006.530) anion exchange column (Metrohm AG). A mixture of $1.0 \mathrm{mM}$ sodium hydrogen carbonate and $3.2 \mathrm{mM}$ sodium carbonate was used as the eluent; $100 \mathrm{mM}$ sulfuric acid was used as the regenerant; injection volume was $100 \mu \mathrm{L}$, and flow rate $0.7 \mathrm{~mL} \mathrm{~min}^{-1}$. Samples were diluted 1000-fold with deionized water (Siemens, $<0.06 \mu S$ ), and filtered using $0.22 \mu \mathrm{m}$ hydrophilic polyvinylidene fluoride membranes (Merck Life Science Private Limited, India), prior to analysis. Sigma-Aldrich (USA) standard chemicals were used to prepare the calibration curve for quantification; overall sample reproducibility was $\pm 0.2 \mathrm{ppm}$. 
655

656

657

658

659

660

661

662

663

664

665

666

667

668

669

670

671

672

673

674

675

676

677

678

679

680

681

682

683

684

685

686

687

688

689

690

691

692

Code availability. All data analysis codes used in this study are in the published domain, and have been appropriately cited in the text.

\section{Data availability}

All nucleotide sequence data have been deposited in NCBI Sequence Read Archive (SRA) or GenBank under the BioProject accession number PRJNA309469: (i) the whole metagenome shotgun sequence datasets have the Run accession numbers SRR3646127 through SRR3646132, SRR3646144, SRR3646145, SRR3646147, SRR3646148, SRR3646150 through SRR3646153, SRR3646155 through SRR3646158, SRR3646160 through SRR3646165; SRR3570036, SRR3570038, SRR3577067, SRR3577068, SRR3577070, SRR3577071, SRR3577073, SRR3577076, SRR3577078, SRR3577079, SRR3577081， SRR3577082, SRR3577086, SRR3577087, SRR3577090, SRR3577311, SRR3577337, SRR3577338, SRR3577341, SRR3577343， SRR3577344, SRR3577345, SRR3577347, SRR3577349, SRR3577350， SRR3577351; SRR3872933， SRR3872934， SRR3884351， SRR3884355, SRR3884357, SRR3884359, SRR3884468, SRR3884472, SRR3884479, SRR3884488, SRR3884538, SRR3884540, SRR3884542, SRR3884544, SRR3884546 through SRR3884548, SRR3884552, SRR3884553 and SRR3884554; (ii) the whole metatranscriptome sequence dataset has the Run accession number SRR7991972; (iii) the whole genome sequences have the GenBank accession numbers SWAW01000000, SSXS01000000, SZNL01000000, SSXT01000000, SWAV01000000 and SWAU01000000.

\section{References}

1. Wright, J. J., Konwar, K. M. \& Hallam, S. J. Microbial ecology of expanding oxygen minimum zones. Nat. Rev. Microbiol. 10, 381 (2012).

2. Fernandes, S. et al. Enhanced carbon-sulfur cycling in the sediments of Arabian Sea oxygen minimum zone center. Sci. Rep. 8, 8665 (2018).

3. Maltby, J., Sommer, S., Dale, A. W. \& Treude, T. Microbial methanogenesis in the sulfatereducing zone of surface sediments traversing the Peruvian margin. Biogeosciences 13, 283-299 (2016).

4. Ulloa, O., Canfield, D. E., DeLong, E. F., Letelier, R. M., \& Stewart, F. J. Microbial oceanography of anoxic oxygen minimum zones. Proc. Natl. Acad. Sci. USA 109, 1599616003 (2012).

5. Bertagnolli, A. D. \& Stewart, F. J. Microbial niches in marine oxygen minimum zones. Nat. Rev. Microbiol. 16, 723-729 (2018).

6. Lam, P. et al. Revising the nitrogen cycle in the Peruvian oxygen minimum zone. Proc. Natl. Acad. Sci. USA 106, $4752-4757$ (2009).

7. Revsbech, N. P. et al. Determination of ultra-low oxygen concentrations in oxygen minimum zones by the STOX sensor. Limnol. Oceanogr-Meth. 7, 371-381 (2009). 
693

694

695

696

697

698

699

700

701

702

703

704

705

706

707

708

709

710

711

712

713

714

715

716

717

718

719

720

721

722

723

724

725

726

727

728

729

730

731

732

733

734

735

736

8. Canfield, D. E. et al. A cryptic sulfur cycle in oxygen-minimum-zone waters off the Chilean coast. Science 330, 1375-1378 (2010).

9. Stolper, D. A., Revsbech, N. P. \& Canfield, D. E. Aerobic growth at nanomolar oxygen concentrations. Proc. Natl. Acad. Sci. USA 107, 18755-18760 (2010).

10. Füssel, J. et al. Nitrite oxidation in the Namibian oxygen minimum zone. ISME J. 6, 12001209 (2012).

11. Riedel, T. E., Berelson, W. M., Nealson, K. H. \& Finkel, S. E. Oxygen consumption rates of bacteria under nutrient-limited conditions. Appl. Environ. Microb. 79, 4921-4931 (2013).

12. Kalvelage, T. et al. Aerobic microbial respiration in oceanic oxygen minimum zones. PloS one 10, e0133526 (2015).

13. Garcia-Robledo, E. et al. Cryptic oxygen cycling in anoxic marine zones. Proc. Natl. Acad. Sci. USA 114, 8319-8324 (2017).

14. Breuer, E. R. et al. Sedimentary oxygen consumption and microdistribution at sites across the Arabian Sea oxygen minimum zone (Pakistan margin). Deep-Sea. Res. Pt II. 56, 296304 (2009).

15. Cavan, E. L., Trimmer, M., Shelley, F. \& Sanders, R. Remineralization of particulate organic carbon in an ocean oxygen minimum zone. Nat. Commun. 8, 14847 (2017).

16. Jessen, G. L. et al. Hypoxia causes preservation of labile organic matter and changes seafloor microbial community composition (Black Sea). Sci. Adv. 3, e1601897 (2017).

17. Acharya, S. S. \& Panigrahi, M. K. Eastward shift and maintenance of Arabian Sea oxygen minimum zone: Understanding the paradox. Deep Sea Res. Part I Oceanogr. Res. Pap. 115, 240-252 (2016).

18. Canfield, D. E., Kristensen, E. \& Thamdrup, B. in Aquatic geomicrobiology 656 (Academic Press, 2005).

19. López, N. I. \& Duarte, C. M. Dimethyl sulfoxide (DMSO) reduction potential in Mediterranean seagrass (Posidonia oceanica) sediments. J. Sea Res. 51, 11-20 (2004).

20. Jørgensen, B. B. \& Kasten, S. in Marine Geochemistry (ed. Schulz, H. D. \& Zabel, M. ) 271-309 (Springer, Berlin, 2006).

21. Lidbury, I., Murrell, J. C. \& Chen, Y. Trimethylamine N-oxide metabolism by abundant marine heterotrophic bacteria. Proc. Natl. Acad. Sci. USA 111, 2710-2715 (2014).

22. Benz, M., Schink, B. \& Brune, A. Humic acid reduction by Propionibacterium freudenreichii and other fermenting bacteria. Appl. Environ. Microbiol. 64, 4507-4512 (1998).

23. He, S., Lau, M. P., Linz, A. M., Roden, E. E. \& McMahon, K. D. Extracellular electron transfer may be an overlooked contribution to pelagic respiration in humic-rich freshwater lakes. mSphere 4, e00436-18 (2019).

24. Janvier, M., Frehel, C., Grimont, F. \& Gasser, F. Methylophaga marina gen. nov., sp. nov. and Methylophaga thalassica sp. nov., marine methylotrophs. Int. J. Syst. Evol. Microbiol. 35, 131-139 (1985).

25. Beudeker, R., Boer, W. \& Kuenen, J. Heterolactic fermentation of intracellular polyglucose by the obligate chemolithotroph Thiobacillus neapolitanus under anaerobic conditions. FEMS Microbiol. Lett. 12, 337-342 (1981).

26. Blazewicz, S. J., Barnard, R. L., Daly, R. A. \& Firestone, M. K. Evaluating rRNA as an indicator of microbial activity in environmental communities: limitations and uses. The ISME J. 7, 2061-2068 (2013). 
27. Johnson, S. S. et al. Ancient bacteria show evidence of DNA repair. Proc. Natl. Acad. Sci. USA 104, 14401-14405 (2007).

28. Lomstein, B. A., Langerhuus, A. T., D'Hondt, S., Jørgensen, B. B. \& Spivack, A. J. Endospore abundance, microbial growth and necromass turnover in deep sub-seafloor sediment. Nature 484, 101-104 (2012).

29. Kempes, C. P., van Bodegom, P. M., Wolpert, D., Libby, E., Amend, J. \& Hoehler, T. Drivers of bacterial maintenance and minimal energy requirements. Front. Microbiol. 8, 110 (2017).

30. Jiang, Y., Xiong, X., Danska, J. \& Parkinson, J. Metatranscriptomic analysis of diverse microbial communities reveals core metabolic pathways and microbiome-specific functionality. Microbiome 4, 2 (2016).

31. Bardiya, N. \& Bae, J-H. Dissimilatory perchlorate reduction: a review. Microbiol. Res. 166, 237-254. (2011).

32. Parker, G. A. \& Smith, J. M. Optimality theory in evolutionary biology. Nature, 348, 27-33 (1990).

33. Moran, et al. Sizing up metatranscriptomics. The ISME J. 7, 237-243 (2013).

34. Rauhut, R. \& Klug, G. mRNA degradation in bacteria. FEMS Microbiol. Rev. 23, 353-370 (1999).

35. Steglich, C., Lindell, D., Futschik, M., Rector, T., Steen, R. \& Chisholm, S. W. Short RNA half-lives in the slow-growing marine cyanobacterium Prochlorococcus. Genome Biol. 11, 2-14 (2010).

36. Hundt, S., Zaigler, A., Lange, C., Soppa, J. \& Klug, G. Global analysis of mRNA decay in Halobacterium salinarum NRC-1 at single-gene resolution using DNA microarrays. J. Bacteriol. 189, 6936-6944 (2007).

37. Steiner, P. A. et al. Highly variable mRNA half-life time within marine bacterial taxa and functional genes. Environ. Microbiol. (2019).

38. Orsi, W., Biddle, J. F. \& Edgcomb, V. Deep sequencing of subseafloor eukaryotic rRNA reveals active fungi across marine subsurface provinces. PLoS One 8, p.e56335 (2013).

39. Ignatov, D. V., Salina, E. G., Fursov, M. V., Skvortsov, T. A., Azhikina, T. L. \& Kaprelyants, A. S. Dormant non-culturable Mycobacterium tuberculosis retains stable low-abundant mRNA. BMC genomics 16, 954 (2015).

40. Orsi, W. D., Edgcomb, V. P., Christman, G. D. \& Biddle, J. F. Gene expression in the deep biosphere. Nature 499, 205-208 (2013).

41. Thureborn, P., Franzetti, A., Lundin, D. \& Sjöling, S. Reconstructing ecosystem functions of the active microbial community of the Baltic Sea oxygen depleted sediments. PeerJ 4, e1593 (2016).

42. Coates, J. D. \& Achenbach, L. A. Microbial perchlorate reduction: rocket-fueled metabolism. Nat. Rev. Microbiol. 2, 569-580 (2004).

43. Carlström, C. I. et al. Physiological and genetic description of dissimilatory perchlorate reduction by the novel marine bacterium Arcobacter sp. strain CAB. MBio 4, e00217-13 (2013).

44. Carlström, C. I. et al. Phenotypic and genotypic description of Sedimenticola selenatireducens strain CUZ, a marine (per) chlorate-respiring gammaproteobacterium, and its close relative the chlorate-respiring Sedimenticola strain NSS. Appl. Environ. Microbiol. 81, 2717-2726 (2015). 
45. Stepanov, V. G., Xiao, Y., Lopez, A. J., Roberts, D. J. \& Fox, G. E. Draft genome sequence of Marinobacter sp. strain P4B1, an electrogenic perchlorate-reducing strain isolated from a long-term mixed enrichment culture of marine bacteria. Genome Announc. 4, e01617-15 (2016).

46. Kamp, A., Høgslund, S., Risgaard-Petersen, N. \& Stief, P. Nitrate storage and dissimilatory nitrate reduction by eukaryotic microbes. Front. Microbiol. 6, 1492 (2015).

47. Olsson, I. U. in Radiocarbon Variations and Absolute Chronology, (eds Olsson, I. U.) 17 (Nobel Symposium, 12th Proc., John Wiley \& Sons, New York, 1970).

48. Fairbanks, R. G. Radiocarbon calibration curve spanning 0 to 50,000 years BP based on paired ${ }^{230} \mathrm{Th} /{ }^{234} \mathrm{U} /{ }^{238} \mathrm{U}$ and ${ }^{14} \mathrm{C}$ dates on pristine corals. Quat. Sci. Rev. 24, 1781-1796 (2005).

49. Stuiver, M. \& Polach, H. A. Discussion Reporting of ${ }^{14} \mathrm{C}$ data. Radiocarbon 19, 355-363 (1977).

50. Ghosh, W. et al. Resilience and receptivity worked in tandem to sustain a geothermal mat community amidst erratic environmental conditions. Sci. Rep. 5, 12179 (2015).

51. Quast, C. et al. The SILVA ribosomal RNA gene database project: improved data processing and web-based tools. Nucleic Acids Res. 41, D590-D596 (2013).

52. Langmead, B. \& Salzberg, S. L. Fast gapped-read alignment with Bowtie2. Nat. Methods 9, 357-359 (2012).

53. Li, D., Liu, C. M., Luo, R., Sadakane, K. \& Lam, T. W. MEGAHIT: an ultra-fast single-node solution for large and complex metagenomics assembly via succinct de Bruijn graph. Bioinformatics 31, 1674-1676 (2015).

54. Mikheenko, A., Saveliev, V. \& Gurevich, A. MetaQUAST: evaluation of metagenome assemblies. Bioinformatics 32, 1088-1090 (2016).

55. Zhu, W., Lomsadze, A., Borodovsky, M. Ab initio gene identification in metagenomic sequences. Nucleic Acids Res. 38, e132 (2010).

56. Nurk, S., et al. Assembling single-cell genomes and mini-metagenomes from chimeric MDA products. J. Comput. Biol. 20, 714-737 (2013).

57. Gurevich, A., Saveliev, V., Vyahhi, N. \& Tesler, G. QUAST: quality assessment tool for genome assemblies. Bioinformatics 29, 1072-1075 (2013).

58. Wick, R. R., Schultz, M. B., Zobel, J. \& Holt, K. E. Bandage: interactive visualization of de novo genome assemblies. Bioinformatics 31, 3350-3352 (2015).

59. Hyatt, D., Chen, G. L., Locascio, P.F., Land, M. L., Larimer, F. W. \& Hauser, L. J. Prodigal: prokaryotic gene recognition and translation initiation site identification. BMC Bioinformatics 11, 119 (2010).

60. Kanehisa, M., Sato, Y., Kawashima, M., Furumichi, M. \& Tanabe, M. KEGG as a reference resource for gene and protein annotation. Nucleic Acids Res. 44, D457-462 (2016).

61. Sutton, S. The most probable number method and its uses in enumeration, qualification, and validation. Microbiol. Top. J. Validation Tech. 16, 35-38 (2010).

62. Alam, M., Pyne, P., Mazumdar, A., Peketi, A. \& Ghosh, W. Kinetic enrichment of ${ }^{34} S$ during proteobacterial thiosulfate oxidation and the conserved role of SoxB in S-S bond breaking. Appl. Environ. Microbiol. 79, 4455-4464 (2013).

63. Ghosh, W. \& Roy, P. Mesorhizobium thiogangeticum sp. nov., a novel sulfur-oxidizing chemolithoautotroph from rhizosphere soil of an Indian tropical leguminous plant. Int. J. Syst. Evol. Microbiol. 56, 91-97 (2006). 
64. Straub, K. L. \& Buchholz-Cleven, B. E. Enumeration and detection of anaerobic ferrous iron-oxidizing, nitrate-reducing bacteria from diverse European sediments. Appl. Environ. Microbiol. 64, 4846-4856 (1998).

65. Lovley, D. R. \& Phillips, E. J. Organic matter mineralization with reduction of ferric iron in anaerobic sediments. Appl. Environ. Microbiol. 51, 683-689 (1986).

66. Myers, C. R. \& Nealson, K. H. Bacterial manganese reduction and growth with manganese oxide as the sole electron acceptor. Science 240, 1319-1321 (1988).

67. So, C. M. \& Young, L. Isolation and characterization of a sulfate-reducing bacterium that anaerobically degrades alkanes. Appl. Environ. Microbiol. 65, 2969-2976 (1999).

68. Oren, A. \& Trüper, H. G. Anaerobic growth of halophilic archaeobacteria by reduction of dimethylsulfoxide and trimethylamine N-oxide. FEMS Microbiol. Lett. 70, 33-36 (1990).

69. Mercier, P., Yerushalmi, L., Rouleau, D. \& Dochain, D. Kinetics of lactic acid fermentation on glucose and corn by Lactobacillus amylophilus. J. Chem. Technol. Biotechnol. 55, 111121 (1992).

70. Balk, M., van Gelder, T., Weelink, S. A. \& Stams, A. J. (Per)chlorate reduction by the thermophilic bacterium Moorella perchloratireducens sp. nov., isolated from underground gas storage. Appl. Environ. Microbiol. 74, 403-409 (2008). 
Table 1. The nine bacterial species isolated from $275 \mathrm{cmbsf}$ of SSK42/6, and the anaerobic/fermentative growth properties of their representative strains.

\begin{tabular}{|c|c|c|c|c|c|c|c|c|c|}
\hline \multirow[b]{2}{*}{$\begin{array}{l}\text { Identification up to lowest } \\
\text { taxonomic level possible }\end{array}$} & \multicolumn{2}{|c|}{$\begin{array}{l}\text { Bacteria isolated } \\
\text { in ASWT }\end{array}$} & \multicolumn{2}{|c|}{$\begin{array}{l}\text { Bacteria isolated } \\
\text { in ASWTY }\end{array}$} & \multicolumn{5}{|c|}{ Bacteria isolated in MSTY } \\
\hline & $\begin{array}{l}\text { Halothiobacillus } \\
\text { sp. }\end{array}$ & $\begin{array}{l}\text { Methylophaga } \\
\text { sp.* }\end{array}$ & Sulfitobacter sp. & $\begin{array}{l}\text { Halomonas } \\
\text { sp. }\end{array}$ & $\begin{array}{l}\text { Stenotrophomonas } \\
\text { sp. }\end{array}$ & $\begin{array}{l}\text { Halomonas } \\
\text { sp. }\end{array}$ & $\begin{array}{l}\text { Pusillimonas } \\
\text { ginsengisoli }\end{array}$ & $\begin{array}{l}\text { Pseudomonas } \\
\text { bauzanensis }\end{array}$ & $\begin{array}{l}\text { Cereibacter } \\
\text { changlaensis }\end{array}$ \\
\hline $\begin{array}{l}\text { Total number of strains } \\
\text { isolated }\end{array}$ & 6 & 2 & 8 & 2 & 1 & 3 & 2 & 2 & 1 \\
\hline $\begin{array}{l}\text { Name of the representative } \\
\text { strain }\end{array}$ & SB14A & $\begin{array}{c}\text { SB9B } \\
= \\
\text { MTCC } 12599\end{array}$ & $\begin{array}{c}15 \text { WGC } \\
= \\
\text { MCC } 3606\end{array}$ & $\begin{array}{c}15 \mathrm{WGF} \\
= \\
\text { MCC } 3301\end{array}$ & SBPC3 & SBBP1 & $\begin{array}{c}\text { SBO3 } \\
= \\
\text { MTCC } 12559\end{array}$ & $\begin{array}{c}\text { SBBB } \\
= \\
\text { MTCC } 12600\end{array}$ & $\begin{array}{c}\text { SBBC } \\
= \\
\text { MTCC } 12557\end{array}$ \\
\hline $\begin{array}{lr}\text { 16S rRNA } & \text { gene } / \text { whole } \\
\text { genome } & \text { sequence } \\
\text { accession of } & \text { the } \\
\text { representative strain } & \\
\end{array}$ & $\begin{array}{l}\text { LN999387/ } \\
\text { SWAW01000000 }\end{array}$ & $\begin{array}{l}\text { LN999390 / } \\
\text { SSXS01000000 }\end{array}$ & $\begin{array}{l}\text { LT607023 / } \\
\text { SZNL01000000 }\end{array}$ & $\begin{array}{l}\text { LT607031/ } \\
\text { SSXT01000000 }\end{array}$ & LN999400 & LN999401 & LN999404 & $\begin{array}{l}\text { LN999396/ } \\
\text { SWAV01000000 }\end{array}$ & $\begin{array}{l}\text { LN999397 / } \\
\text { SWAU01000000 }\end{array}$ \\
\hline \multicolumn{10}{|c|}{ Anaerobic growth/survival in liquid cultures using electron acceptors other than $\mathrm{O}_{2}$} \\
\hline $\begin{array}{l}\text { Media used to check } \\
\text { anaerobic growth }^{\S}\end{array}$ & ASWT & ASWM & ASWTY & ASWTY & MSTY & MSTY & MSTY & MSTY & MSTY \\
\hline $\begin{array}{l}\mathrm{CFU}^{\#} \text { present } \mathrm{mL}^{-1} \text { culture } \\
\text { at } \mathrm{O} \text { incubation }\end{array}$ & $6 * 10^{4}$ & $6.1^{*} 10^{4}$ & $2 * 10^{4}$ & $3.8^{*} 10^{4}$ & $7.8^{*} 10^{4}$ & $4.5^{\star} 10^{4}$ & $1.9^{*} 10^{4}$ & $5.1 * 10^{4}$ & $2.6^{*} 10^{4}$ \\
\hline $\begin{array}{l}\mathrm{CFU}^{\#} \text { present } \mathrm{mL}^{-1} \text { culture } \\
\text { after } 10 \text { days incubation }\end{array}$ & $2.8^{*} 10^{3}$ & 0 & 0 & 0 & $1.6^{*} 10^{7}$ & $9 * 10^{7}$ & $2.3^{*} 10^{7}$ & 0 & 0 \\
\hline \multicolumn{10}{|c|}{ Fermentative growth/survival in liquid cultures incubated under anaerobic condition } \\
\hline $\begin{array}{l}\text { Media used to check } \\
\text { fermentative growth }\end{array}$ & ASWT & ASWMF & ASWTYP & ASWTYP & NA & NA & NA & MSTYP & MSTYP \\
\hline $\begin{array}{l}\mathrm{CFU}^{\#} \text { present } \mathrm{mL}^{-1} \text { culture } \\
\text { at } \mathrm{O} \text { incubation }\end{array}$ & $7.9^{*} 10^{4}$ & $7.8^{*} 10^{4}$ & $2.2^{*} 10^{4}$ & $3.5^{*} 10^{4}$ & NA & NA & NA & $6^{*} 10^{4}$ & $2.5^{\star} 10^{4}$ \\
\hline $\begin{array}{l}\mathrm{CFU}^{\#} \text { present } \mathrm{mL}^{-1} \text { culture } \\
\text { after } 5 \text { days incubation }\end{array}$ & NR & $2.8^{*} 10^{4}$ & 0 & 0 & NA & NA & NA & $1.6^{*} 10^{3}$ & 0 \\
\hline $\begin{array}{l}\mathrm{CFU}^{\#} \text { present } \mathrm{mL}^{-1} \text { culture } \\
\text { after } 15 \text { days incubation }\end{array}$ & $2.8^{*} 10^{3}$ & 0 & NA & NA & NA & NA & NA & $\mathrm{NR}$ & NA \\
\hline $\begin{array}{l}\mathrm{CFU}^{\#} \text { present } \mathrm{mL}^{-1} \text { culture } \\
\text { after } 45 \text { days incubation }\end{array}$ & NR & NA & NA & NA & NA & NA & NA & 0 & NA \\
\hline $\begin{array}{l}\mathrm{CFU}^{\#} \text { present } \mathrm{mL}^{-1} \text { culture } \\
\text { after } 60 \text { days incubation }\end{array}$ & $3.7^{*} 10^{2}$ & NA & NA & NA & NA & NA & NA & NA & NA \\
\hline $\begin{array}{l}\mathrm{CFU}^{\#} \text { present } \mathrm{mL}^{-1} \text { culture } \\
\text { after } 80 \text { days incubation }\end{array}$ & $4.4^{*} 10^{1}$ & NA & NA & NA & NA & NA & NA & NA & NA \\
\hline $\begin{array}{l}\text { CFU }^{\#} \text { present } \mathrm{mL}^{-1} \text { culture } \\
\text { after } 100 \text { days incubation }\end{array}$ & 0 & NA & NA & NA & NA & NA & NA & NA & NA \\
\hline
\end{tabular}

* While all isolates were maintained, and tested for anaerobic growth, in their respective isolation-media, Methylophaga was maintained/tested in ASW-methanol (ASWM).

$5 \quad$ MSTYP = MSTY medium supplemented with pyruvate; ASWTYP = ASWTY medium supplemented with pyruvate; ASWMF = ASWM medium supplemented with fructose; full-forms of all the other abbreviated media names are available in the text. NA = Not applicable; NR $=$ Not recorded.

$\S$ All media-types used to check anaerobic growth/survival were supplemented with $\mathrm{MnO}_{2}, \mathrm{Na}_{2} \mathrm{SO}_{4}, \mathrm{NaNO}_{3}, \mathrm{Fe}_{2} \mathrm{O}_{3},\left(\mathrm{CH}_{3}\right)_{2} \mathrm{SO}$ and $\left(\mathrm{CH}_{3}\right)_{3} \mathrm{NO}$.

\# CFU or colony forming units present were counted by taking out $1 \mathrm{ml}$ of the liquid culture, then plating individual dilution grades onto triplicate agar plates of the corresponding media and incubating the plates aerobically. Colony-counts in the different dilution-plates (checked until no further colony appeared) were multiplied by corresponding dilution factors, then summed-up across all the plates, and finally averaged to get the number of CFU present $\mathrm{mL}^{-1}$ of the liquid culture. 


\section{Legends}

Figure 1. Age versus depth models and sedimentation rates, total organic carbon (TOC) contents (in wt \%), hydrogen sulfide concentrations (in $\mu \mathrm{M}$ ) and methane concentrations (in $\mu \mathrm{M}$ ) along the cores (a-d) SSK42/5 and (e-h) SSK42/6. Sedimentation rates in both the cores were found to 5 increase at around $6800 \mathrm{yr} \mathrm{BP}$, and remain high towards the core-tops. Data for TOC, hydrogen sulfide and methane were taken from Fernandes et al. (2018) ${ }^{2}$.

Figure 2. Heat map comparing the percentages of metagenomic reads from individual sedimentsamples of (a) SSK42/5, (b) SSK42/6 and (c) SSK42/9 that matched with genomic sequences of the six obligately aerobic bacterial isolates: (Ceb) Cereibacter changlaensis MTCC 12557, $(H \mathrm{~lm})$ Halomonas sp. MCC 3301, (HIt) Halothiobacillus sp. SB14A, (Mtp) Methylophaga sp. MTCC 12599, (Psu) Pseudomonas bauzanensis MTCC 12600, and (Sul) Sulfitobacter sp. MCC 3606. For each percentage value, its $\log _{10}$ has been plotted in the $z$ axis of the heat map, so as to resolve the wide span of the data. Percentage level of matched reads for individual pairs of metagenomic-genomic datasets ranged between 0 and 19.05, with intermediate values in the order of $10^{-2}$ to $10^{1}$. Since 0 is less than any minimum value possible in the log scale, it is noteworthy that the deepest blue squares of panels $B$ and $C$, which apparently match the order of $10^{-3}$ in the color scale, actually correspond to the real values 0 (see Supplementary Table 16).

\section{Acknowledgements}

Financial support for conducting the microbiological studies was provided by given by Bose Institute via internal faculty grants and Earth System Science Organization, Ministry of Earth Sciences (MoES), Government of India (Gol) via grant number MoES/36/00IS/Extra/19/2013. We thank the Director CSIR-National Institute of Oceanography for facilitating the geochemical studies and the research cruise SSK42 for acquisition of sediment cores. MoES (GAP2303) also funded the research cruise. All the support received from the CSIR-NIO Ship Cell members and the crew members of SSK42 is gratefully acknowledged. S.B. and M.A. received fellowship from Bose Institute. C.R. and MJR got fellowship from University Grants Commission, Gol. SM got fellowship from Department of Science and Technology, Gol. J.S., S.F., R.R. and P.P received fellowships from Council of Scientific and Industrial Research, Gol. N.M. got fellowship from Science and Engineering Research Board, Gol, under the grant EMR/2016/002703. We thank Werner Liesack (Max Planck Institute for Terrestrial Microbiology, Germany), Fumio Inagaki (Japan Agency for Marine-Earth Science and Technology, Japan) and Subhra Kanti Mukhopadhyay (University of Burdwan, India) for useful discussions. 


\section{Author contributions}

W.G. conceived the study, designed the experiments, interpreted the results and wrote the paper. S.B. anchored the whole microbiological study, performed the experiments, and analyzed and curated the data. A.M. led the mission SSK42 and all geochemical investigations therein. R.C. and

5 A.M. participated in result interpretation and made intellectual contributions. C.R., M.J.R., J.S., T.M. and M.A. performed bioinformatic and microbiological data analyses. S.M., R.R., N.M., P.P. and P.K.H. performed microbiological experiments. S.F. and A.P. performed geochemical experiments. All authors read and vetted the manuscript.

\section{Additional information}

Supplementary Information and Dataset accompany the online version of the paper.

Competing interest: The authors declare no competing interest. 


\section{SSK $42 / 5$}

a 仓 छ

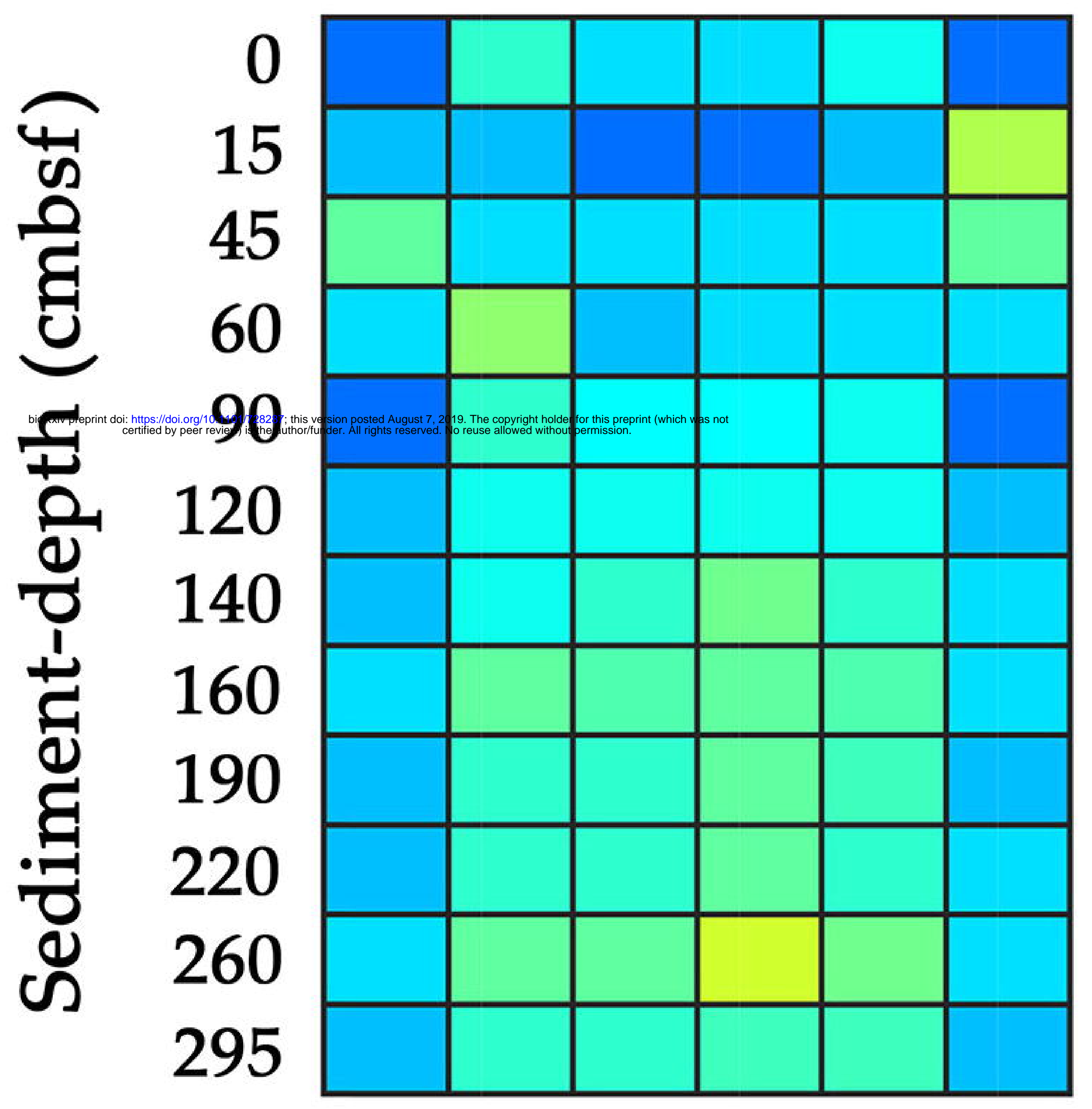

SSK $42 / 6$

b

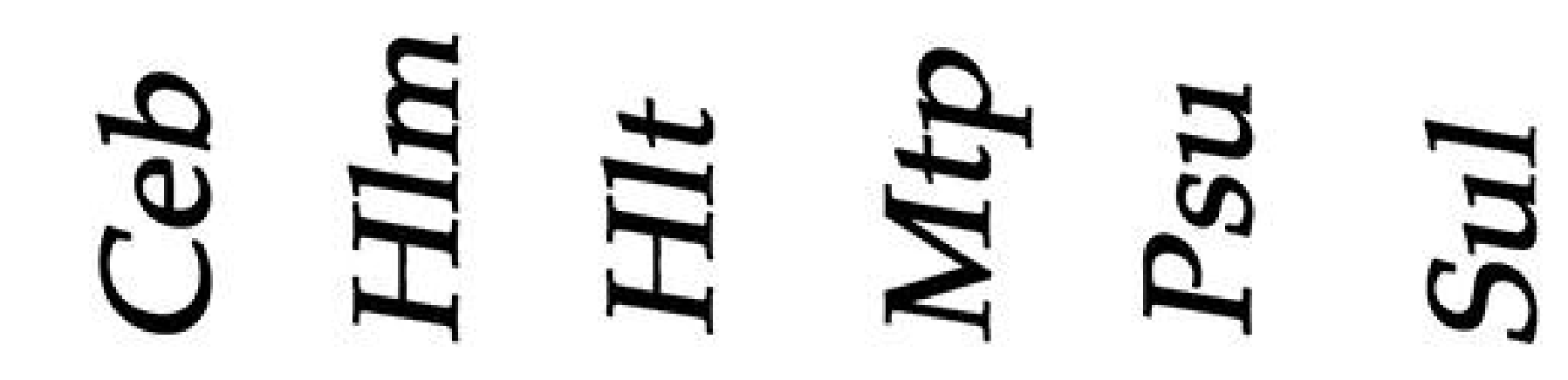

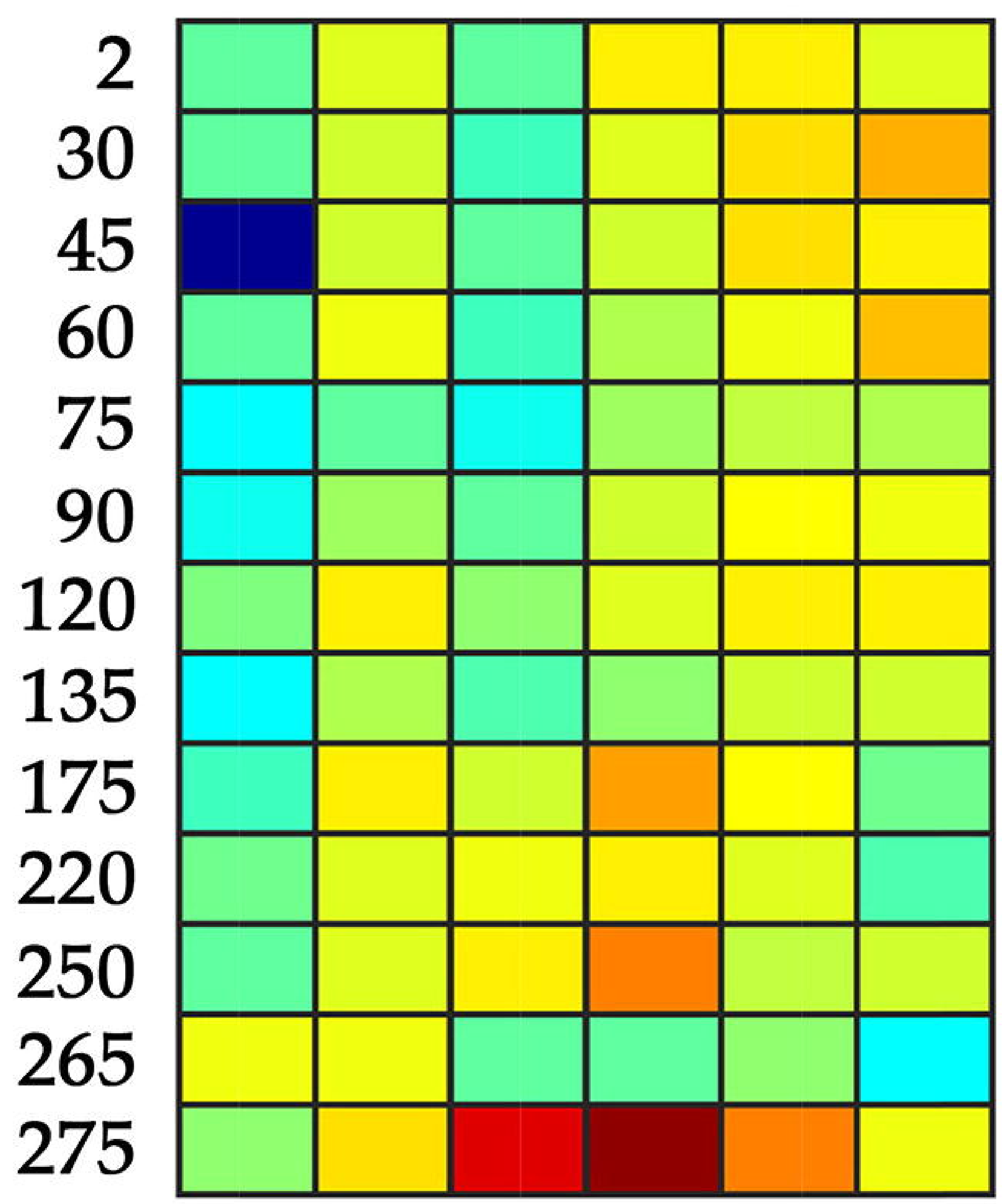

SSK42/9

C 过吉志蛋

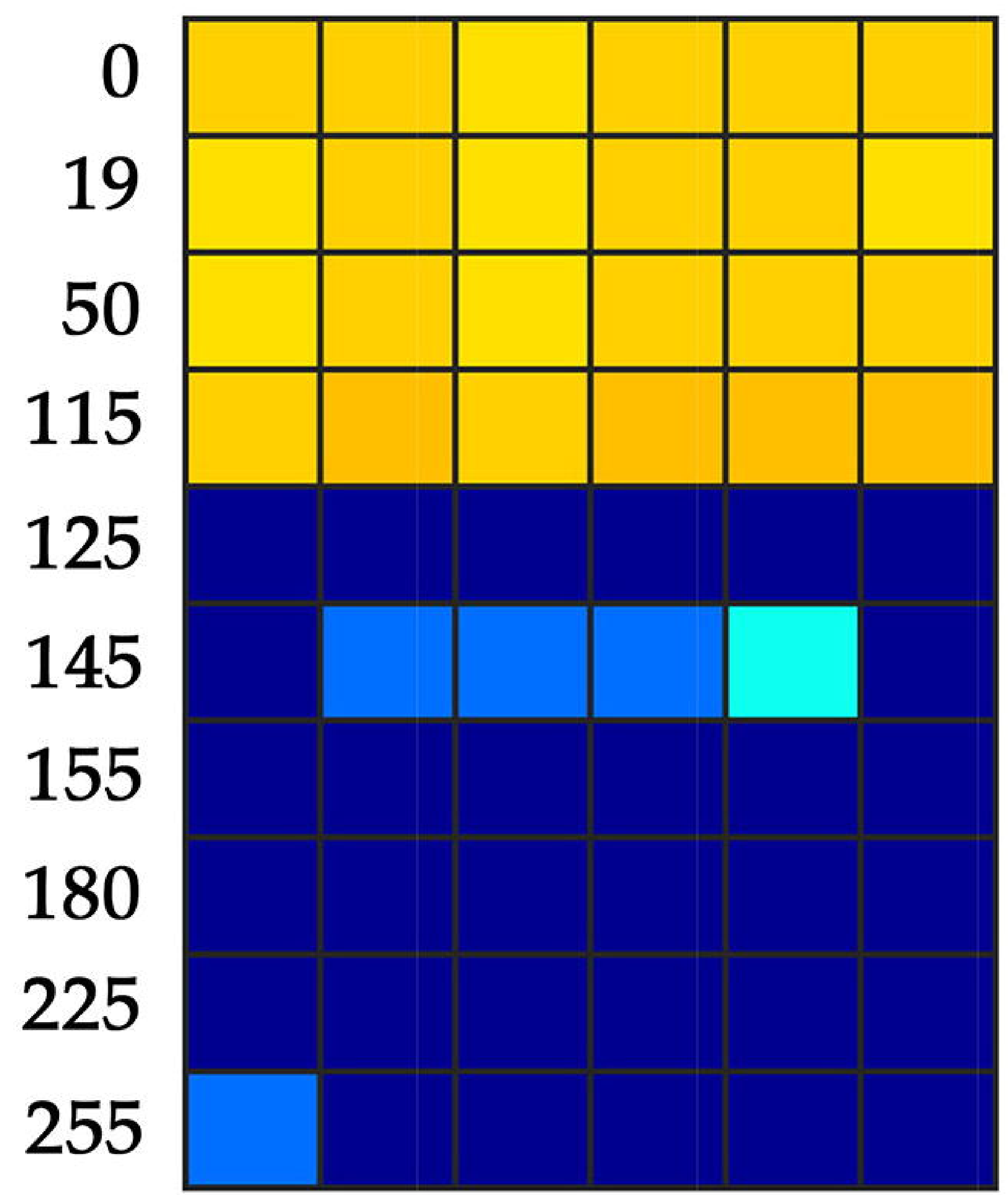

$10^{-2}$

$10^{-1}$ 